UNIVERSIDADE FEDERAL DE JUIZ DE FORA

FACULDADE DE EDUCAÇÃO FÍSICA E DESPORTOS PROGRAMA DE PÓS-GRADUAÇÃO EM EDUCAÇÃO FÍSICA

JHONATAN MARQUES MACHADO

IMPACTO DA PANDEMIA DA COVID 19 NO TROFÉU BRASIL DE ATLETISMO

Juiz de Fora 


\section{IMPACTO DA PANDEMIA DA COVID 19 NO TROFÉU BRASIL DE ATLETISMO}

Dissertação apresentada ao Programa de Pósgraduação em Educação Física, área de concentração Exercício e Esporte, da Universidade Federal de Juiz de Fora, como requisito parcial para obtenção do título de mestre.

Orientador: Prof. Dr. Jorge Roberto Perrout de Lima

Juiz de Fora 
Ficha catalográfica elaborada através do programa de geração automática da Biblioteca Universitária da UFJF

com os dados fornecidos pelo(a) autor(a)

Machado, Jhonatan Marques.

Impacto da pandemia da Covid-19 no Troféu Brasil de Atletismo / Jhonatan Marques Machado. -- 2021.

$50 \mathrm{f}$.

Orientador: Jorge Roberto Perrout de de Lima

Dissertação (mestrado acadêmico) - Universidade Federal de Juiz de Fora, Faculdade de Educação Física. Programa de Pós-Graduação em Educação Física, 2021.

1. Atletismo. 2. Pandemia. 3. Desempenho Atlético. I. de Lima, Jorge Roberto Perrout de, orient. II. Título. 
Jhonatan Marques Machado

Impacto da Pandemia da COVID 19 no Troféu Brasil de Atletismo

Dissertação apresentada ao Programa de Pósgraduação em Educação Física da Universidade Federal de Juiz de Fora como requisito parcial à obtenção do título de Mestre em Educação Física. Area de concentração: Exercício e Esporte

Aprovada em 19 de março de 2021

BANCA EXAMINADORA

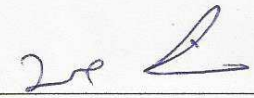

Dr. Jorge Roberto Perrout de Lima - Orientador

Universidade Federal de Juiz de Fora

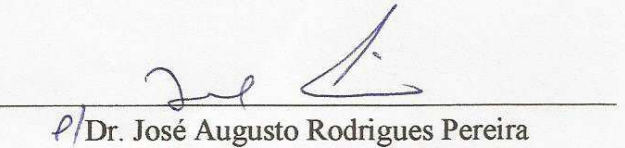

Universidade Federal de Juiz de Fora

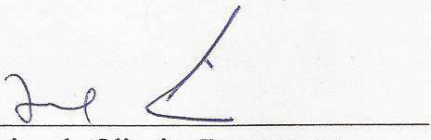

Pf Dr. Vinicius de Oliveira Damasceno

Universidade Federal de Pernambuco 


\section{AGRADECIMENTOS}

Agradeço a Deus por ter me dado forças para seguir em frente.

Ao meu irmão Jeferson Marques Machado (in memoriam) que foi meu primeiro incentivador no esporte.

Aos meus pais Edmilson da Cruz Machado e Silvia Helena Marques Machado, que sem o apoio deles jamais estaria aqui.

Ao meu irmão Jhosef Marques Machado, meu reflexo, a quem me orgulho de ser alguém em quem ele possa se inspirar.

Ao meu orientador Jorge Perrout, que através de nossas conversas nas pistas, sempre prezou pela minha capacidade intelectual com cobranças precisas, e que tenho orgulho em tê-lo como orientador.

Aos meus amigos treinadores e treinadoras que passaram pelo Projeto Cria UFJF, aos quais me inspirei, e tenho enorme admiração pelo que fazem, dentre eles, Marcus Vinicius Silva, Jefferson Verbena, Renato Siqueira, Pablo Domingues e Aline Araújo.

À minha família do Brasil em Portugal, Daniel Lucena, Bianca Cardoso e Felipe Fernandes, que sempre acreditaram em mim, e tenho um enorme carinho e admiração por todos eles.

Ao meu grupo de atletas e todos do projeto de extensão Equipe de Atletismo, com os quais aprendi muito mais que ensinei, levo todos vocês no meu coração.

Aos meus professores e professoras que ao longo dos meus anos acadêmicos, sobretudo aos professores do programa de pós-graduação em educação física da UFJF, são pessoas que tenho admiração e o respeito, pelas pessoas que são, e saber que tenho uma pequena parte dos vossos conhecimentos só me faz engrandecer.

Aos professores que estão compondo a banca, professor Guto e professor Damasceno, tenho certeza que vossos apontamentos só tendem a acrescer ao trabalho. 


\section{RESUMO}

Eventos e clubes esportivos de diversos lugares do mundo sofreram com modificações nos treinamentos e competições devido a pandemia da Covid-19. Seriam estas mudanças capazes de afetar no desempenho esportivo dos atletas? O presente estudo tem como objetivo testar a hipótese se o ano de 2020 foi capaz de influenciar no desempenho dos atletas finalistas do Troféu Brasil de Atletismo. Comparamos os resultados dos finalistas masculinos e femininos dos últimos 4 anos (2017-2020) das provas mais frequentes da competição. Somente a prova dos $10000 \mathrm{~m}$ apresentou diferença significativa no ano de 2020. Portanto, apesar de ser um ano atípico para treinamentos e competições, o ano de 2020 com a pandemia da Covid-19 não impactou a participação, nem os resultados dos atletas finalistas do Troféu Brasil de Atletismo 2020.

Palavras-chave: Atletismo; Pandemia; Desempenho Atlético; 


\begin{abstract}
Sports clubs and events from around the world suffered from changes in training and competitions due to the covid-19 pandemic. Are these changes capable of affecting the athletes' sports performance? The present study aims to test the hypothesis if the year 2020 was able to influence on performance of the finalists of the Brazil Athletics Trophy. We compared the results of the male and female finalists from the last 4 years (20172020) of the most frequent events in the competition. Only the $10,000 \mathrm{~m}$ race showed a significant difference in the year 2020. Therefore, despite being an atypical year for training and competitions, the year 2020 with the Covid-19 pandemic did not impact the participation and the results of the finalists of the Brazil Athletics Trophy 2020.
\end{abstract}

Keywords: Track and Field; Pandemic; Athletic Performance 


\section{LISTA DE FIGURAS}

FIGURA 1 - RESULTADOS DOS FINALISTAS DOS 100 M RASOS FEMININO (PAINEL DA ESQUERDA) E MASCULINO (PAINEL DA DIREITA), NOS ANOS DE 2017-2020. 23

FIGURA 2 - RESULTADOS DOS FINALISTAS DOS 200 M RASOS FEMININO (PAINEL DA ESQUERDA) E MASCULINO (PAINEL DA DIREITA), NOS ANOS DE 2017-2020.

FIGURA 3 - RESULTADOS DOS FINALISTAS DOS 100/110 M COM BARREIRAS FEMININO (PAINEL DA ESQUERDA) E MASCULINO (PAINEL DA DIREITA), NOS ANOS DE 2017-2020. 24

FIGURA 4 - RESULTADOS DOS FINALISTAS DOS 400 M COM BARREIRAS FEMININO (PAINEL DA ESQUERDA) E MASCULINO (PAINEL DA DIREITA), NOS ANOS DE 2017-2020 .....

FigURA 5 - RESULTADOS DOS FINALISTAS DOS 400 M FEMININO (PAINEL DA ESQUERDA) E MASCULINO (PAINEL DA DIREITA), NOS ANOS DE 2017-2020.

FIGURA 6 - RESULTADOS DOS FINALISTAS DOS 800 M FEMININO (PAINEL DA ESQUERDA) E MASCULINO (PAINEL DA DIREITA), NOS ANOS DE 2017-2020.

FIGURA 7 - RESULTADOS DOS FINALISTAS DOS 1500 M FEMININO (PAINEL DA ESQUERDA) E MASCULINO (PAINEL DA DIREITA), NOS ANOS DE 2017-2020...

FIGURA 8 - RESULTADOS DOS FINALISTAS DOS 3000 M OBST. FEMININO (PAINEL DA ESQUERDA) E MASCULINO (PAINEL DA DIREITA), NOS ANOS DE 2017-2020. 26

FIGURA 9 - RESULTADOS DOS FINALISTAS DOS 5000 M FEMININO (PAINEL DA ESQUERDA) E MASCULINO (PAINEL DA DIREITA), NOS ANOS DE 2017-2020...

FIGURA 10 - RESULTADOS DOS FINALISTAS DOS 10000 M FEMININO (PAINEL DA ESQUERDA) E MASCULINO (PAINEL DA DIREITA), NOS ANOS DE 2017-2020.

FIGURA 11 - RESULTADOS DOS FINALISTAS DO SALTO EM DISTÂNCIA FEMININO (PAINEL DA ESQUERDA) E MASCULINO (PAINEL DA DIREITA), NOS ANOS DE 2017-2020

FIGURA 12 - RESULTADOS DOS FINALISTAS DO SALTO EM ALTURA FEMININO (PAINEL DA ESQUERDA) E MASCULINO (PAINEL DA DIREITA), NOS ANOS DE 2017-2020

FIGURA 13 - RESULTADOS DOS FINALISTAS DO SALTO COM VARA FEMININO (PAINEL DA ESQUERDA) E MASCULINO (PAINEL DA DIREITA), NOS ANOS DE 2017-2020

FIGURA 14 - RESULTADOS DOS FINALISTAS DO SALTO TRIPLO FEMININO (PAINEL DA ESQUERDA) E MASCULINO (PAINEL DA DIREITA), NOS ANOS DE 2017-2020.

FIGURA 15 - RESULTADOS DOS FINALISTAS DO LANÇAMENTO DO DISCO FEMININO (PAINEL DA ESQUERDA) E MASCULINO (PAINEL DA DIREITA), NOS ANOS DE 2017-2020 28

FIGURA 16 - RESULTADOS DOS FINALISTAS DO LANÇAMENTO DO DARDO FEMININO (PAINEL DA ESQUERDA) E MASCULINO (PAINEL DA DIREITA), NOS ANOS DE 2017-2020.... 28

FIGURA 17 - RESULTADOS DOS FINALISTAS DO LANÇAMENTO DO MARTELO FEMININO (PAINEL DA ESQUERDA) E MASCULINO (PAINEL DA DIREITA), NOS ANOS DE 2017-2020.

FIGURA 18 - RESULTADOS DOS FINALISTAS DO ARREMESSO DO PESO FEMININO (PAINEL DA ESQUERDA) E MASCULINO (PAINEL DA DIREITA), NOS ANOS DE 2017-2020

FIGURA 19 - RESULTADOS DOS FINALISTAS DOS 20 KM EM MARCHA ATLÉTICA FEMININO (PAINEL DA ESQUERDA) E MASCULINO (PAINEL DA DIREITA), NOS ANOS DE 2017-2020 .... 29

FIGURA 20 - RESULTADOS DOS FINALISTAS DAS COMBINADAS: HEPTATLO FEMININO (PAINEL DA ESQUERDA) E DECATLO MASCULINO (PAINEL DA DIREITA), NOS ANOS DE 2017-2020 ....... 30 


\section{LISTA DE TABELAS}

TABELA 1 - ÍNDICES SOLICITADOS PELA CBAT PARA PARTICIPAÇÃO DO TB NOS ANOS DE 2017 A 2020. 17

TABELA 2 - ESPAÇO TEMPORAL PARA OBTENÇÃO DOS ÍNDICES DO TB …........................... 18

TABELA 3 - QUANTIDADE DE ATLETAS INSCRITOS NO TB ............................................ 18

TABELA 4 - QuANTIDADE DE ATLETAS FINALISTAS NO TB DE 2017 A 2020 POR ESTADO 19

TABELA 5 - QUANTIDADE DE ATLETAS FINALISTAS NO TB DE 2017 A 2020 SEPARADOS

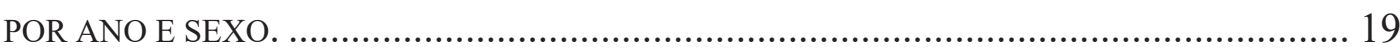

TABELA 6 - DistribuiçÃo dos ATLETAS FINALISTAS NAS DIFERENTES PROVAS DO TB. . 20

TABELA 7 - COMPARAÇÃO DA PERFORMANCE DOS ATLETAS DO TB EM RELAÇÃO A PROVA,

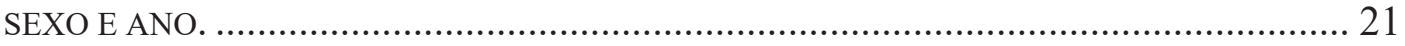

TABELA 8 - COMPARAÇÃO ENTRE OS ÚLTIMOS MEDALHISTAS E NÃO MEDALHISTAS DO TB SEPARADO POR SEXO, PROVA E ANO 31 


\section{LISTA DE ABREVIATURAS E SIGLAS}

CBAt - Confederação Brasileira de Atletismo

COB - Comitê Olímpico Brasileiro

COI - Comitê Olimpico Internacional

OMS - Organização Mundial da Saúde

TB - Troféu Brasil de Atletismo

WA - Worlds Athletics - Federação Internacional de Atletismo 


\section{Sumário}

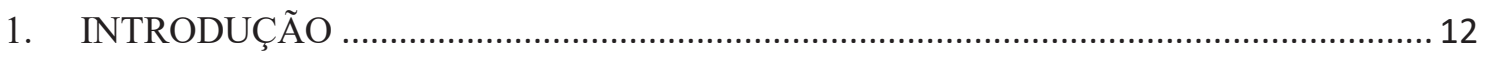

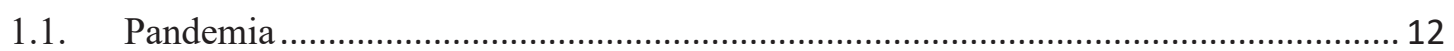

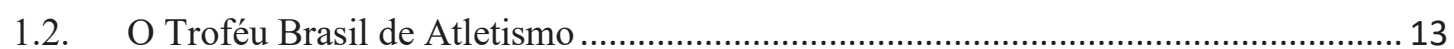

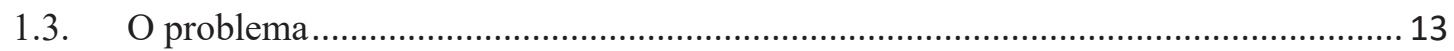

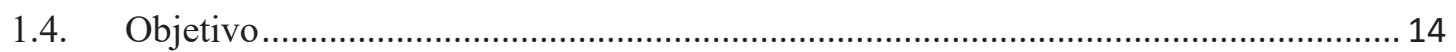

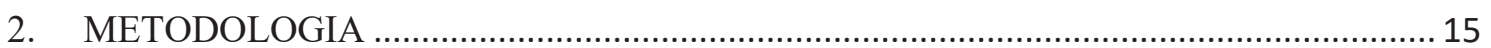

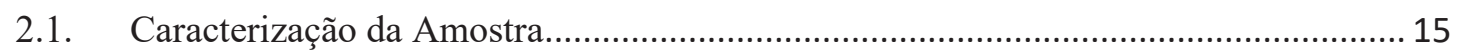

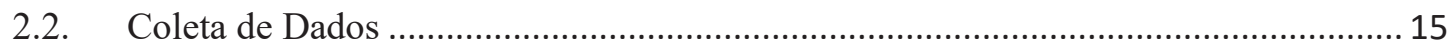

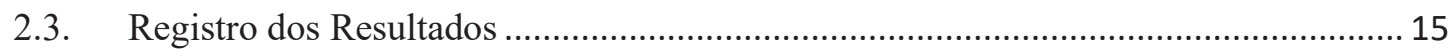

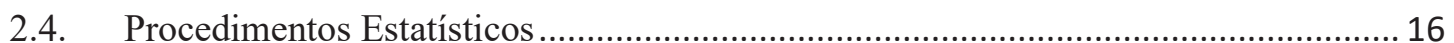

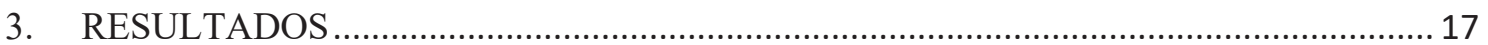

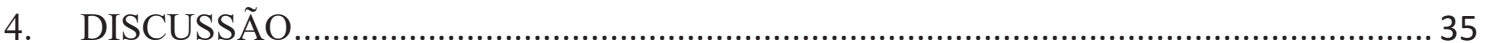

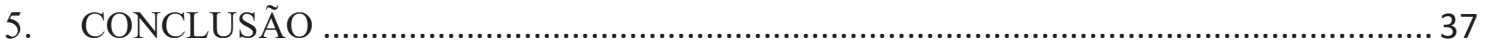

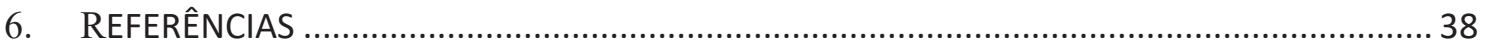

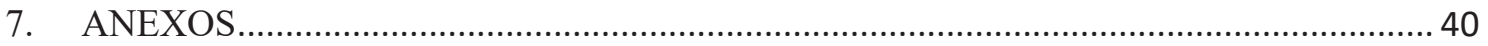




\section{INTRODUÇÃO}

\subsection{Pandemia}

Segundo a OMS (2010) o termo pandemia é a propagação mundial de uma nova doença. Este termo passa a ser usado quando uma epidemia, surto que atinge uma região, se espalha por diferentes continentes com transmissão sustentada de pessoa para pessoa.

No fim do ano de 2019 foi descoberto um novo vírus, o SARS-COVID19, em Wuhan, província de Hubei, na China (LI et al., 2020). Ainda sem muitas explicações do surgimento do vírus, a OMS no dia 11 de Março de 2020 declarou estado de pandemia ao reconhecer que o vírus havia chegado a 114 países e causado mais de 4 mil mortes naquele momento (OMS, 2020a). Dias após, o governo do Brasil através de seu presidente declara estado de calamidade pública em função do Covid-19 (BRASIL, 2020).

Com o início da pandemia, uma série de recomendações são criadas pela OMS para diminuir a propagação do surto do coronavírus, como manter um distanciamento físico e social, manter-se em locais bem ventilados, evitar multidões, limpar as mãos frequentemente e usar máscaras de modo a cobrir nariz, boca e queixo sempre em proximidade de outras pessoas (OMS, 2020b).

Estas medidas de afastamento social impactaram o comportamento da população em geral, com interrupções na rotina diária das pessoas, o fechamento de escolas, faculdades, universidades e empresas. Pode-se afirmar que houve aumento no comportamento sedentário dos indivíduos, além de redução significativa na atividade física. (ZHENG et al., 2020)

Eventos e clubes esportivos de diversos lugares do mundo sofreram com modificações nos treinamentos e competições (DREWES; DAUMANN; FOLLERT, 2020; JÚNIOR; MENDONÇA; TOSCANO, 2020; WONG et al., 2020). Entre os principais eventos impactados, o adiamento do Jogos Olímpicos de Tóquio foi o mais importe (COI, 2020).

Como era esperado, os eventos em solo brasileiro, sobretudo eventos de atletismo, também sofreram suas modificações, alguns de modo inicial foram adiados, outros de fato cancelados (CBAT, 2020a). Impactando, assim, o calendário esportivo de 2020, como o cancelamento de campeonatos estaduais de atletismo (CBAT, 2020b). 
Os clubes e organizações recorreram a diversas formas de treinamento para evitar a perda de desempenho atlético em meio a um calendário esportivo indefinido, e até mesmo sem estrutura e local de treinamento adequados (CBAT, 2020c; SAMUEL RESENDE; DANIEL SILVEIRA, 2020).

Com todas essas as mudanças no mundo ocorrendo, a Federação Internacional de Atletismo (WA - World Athletics) suspendeu o período de índices para os Jogos Olímpicos até dia 1 de dezembro (WORLD ATHLETICS, 2020b).

\subsection{O Troféu Brasil de Atletismo}

A primeira edição do Troféu Brasil de Atletismo foi realizada em 1945, em São Paulo, substituindo a Taça Adhemar de Barros que existiu nos anos de 1940 a 1942. Pelo regulamento inicial, o campeão seria definido pelo clube que conseguisse o maior número de vitórias em 10 edições que aconteciam em até mais de uma vez por ano (CBAT, 2020d).

Ainda segundo a CBAT (2020d), o Troféu Brasil passou a ser anual após o ano de 1982 Tendo como campeões a Funilense (SP) 10 vezes consecutivas, sendo substituída pela BM\&FBovespa que ganhou 13 títulos seguidos até 2016. Além do EC Pinheiros como clube campeão dos anos 2016 a 2020.

O Troféu Brasil leva o nome de Troféu Brasil Caixa de Atletismo desde o ano de 2001. Sendo um dos torneios mais importantes da américa latina, grandes nomes do atletismo brasileiro já se sagraram campeões, e os atletas participam do torneio como forma de obter os índices olímpicos (CBAT, 2020d).

A realização do Troféu Brasil do ano de 2020 definida em dezembro vem como forma regularizar o calendário esportivo da modalidade no ano de 2020, e atender os critérios do COI que suspendeu as marcas para as Olímpiadas de Tóquio no período de março a novembro, sendo reaberta a janela de índice no mês de dezembro. (CBAT, 2020e).

\subsection{O problema}

Devido ao fechamento dos locais de treinamento e dificuldade nos treinamentos reportados por atletas de diversos locais do país, modificações no calendário competitivo da modalidade e a falta de competições estaduais, é possível que essas 
adversidades tenham influenciado na performance atlética dos atletas de no Troféu Brasil 2020.

\subsection{Objetivo}

Verificar se a pandemia da covid-19 no ano de 2020, com todas suas as implicações, impactou na participação e nos resultados dos atletas finalistas do Troféu Brasil de Atletismo 2020. 


\section{METODOLOGIA}

\subsection{Caracterização da Amostra}

Foram analisados os resultados do Troféu Brasil Caixa de Atletismo dos anos 2017 a 2020. Para critérios de seleção, a prova deveria ser recorrente nos últimos 4 anos do torneio. Foram então, descartadas as provas de 50km marcha dos anos 2017 e 2019; e a prova de $35.000 \mathrm{~m}$ Marcha do ano 2020. De cada prova analisada, foram utilizados os resultados dos atletas finalistas e/ou 8 primeiros colocados que concluíram a prova. Neste caso foram excluídos atletas finalistas que foram desclassificados de acordo com as Regras Oficiais do Atletismo e atletas que não obtiveram marca válida.

\subsection{Coleta de Dados}

O número de atletas participantes foi obtido nas inscrições válidas, diretamente do site da competição de cada ano, na aba participantes. Foram coletados os resultados dos atletas participantes do evento "Final" de cada prova. Para eventos onde a final era por tempo, foram adotados critérios de seleção a partir do "Classificação Final" de todas as séries.

Os resultados foram coletados diretamente do site da CBAt http://www.cbat.org.br/novo/ no diretório Competições/ Resultados/ Anos anteriores.

\subsection{Registro dos Resultados}

Após selecionar e baixar os arquivos de dados dos resultados oficiais do Troféu Brasil, os resultados foram transcritos para o software estatístico SPSS. Indicando as seguintes variáveis:

- $\quad \mathrm{N}^{\mathrm{o}}$ de Registro CBAT

- Sexo

- Clube

- Estado

- Prova

- Ano

- Marca Obtida 
Como forma de padronização e análise, todos os eventos de pista foram relatados seus resultados em segundos (s) e os de campo em metros (m). Somente a prova Combinadas Heptatlo/Decatlo foi apresentada seus resultados por pontos.

\subsection{Procedimentos Estatísticos}

Para análise dos dados, foi utilizado o programa estatístico SPSS 27 realizando as operações de estatística descritiva, frequência, média e desvio padrão das variáveis. Além disto, foi usado o teste ANOVA para identificar diferenças significativas da variável Marca Obtida, pela variável Ano. Foi adotado o $\alpha$ de 0,05 . 


\section{RESULTADOS}

O Troféu Brasil é a principal competição adulta entre clubes da Confederação Brasileira de Atletismo. A competição, com duração de 4 dias em 7 etapas, distribuindo suas provas de pista e campo pela pista de atletismo. Além de normas específicas como ser brasileiro e estar vinculado a um clube federado, são estabelecidos índices mínimos de participação. O TB adota os índices de participação conforme a Tabela 1.

Tabela 1. Índices exigidos pela CBAt para participação do TB nos anos de 2017 a 2020.

\begin{tabular}{ccccc}
\hline \multirow{2}{*}{ Provas } & \multicolumn{2}{c}{ Feminino } & \multicolumn{2}{c}{ Masculino } \\
& Média & DP & Média & DP \\
\hline 100 m (s) & 11,94 & 0,17 & 10,53 & 0,10 \\
200 m (s) & 24,47 & 0,24 & 21,40 & 0,17 \\
100/110 m c/ Barreiras (s) & 14,54 & 0,25 & 14,69 & 0,14 \\
$400 \mathrm{~m}$ c/ Barreiras (s) & 64,81 & 3,08 & 54,16 & 1,08 \\
400 m (s) & 56,31 & 0,67 & 47,77 & 0,24 \\
800 m (s) & 136,61 & 2,41 & 112,96 & 1,29 \\
1500 m (s) & 288,34 & 7,71 & 236,99 & 3,35 \\
3000 m Obst. (s) & 753,56 & 19,00 & 580,57 & 13,17 \\
5000 m (s) & 1088,07 & 30,07 & 889,64 & 11,42 \\
10000 m (s) & 2354,51 & 53,04 & 1889,40 & 25,05 \\
Salto em Distância (m) & 5,86 & 0,11 & 7,44 & 0,15 \\
Salto em Altura (m) & 1,69 & 0,05 & 2,02 & 0,03 \\
Salto com Vara (m) & 3,35 & 0,06 & 4,49 & 0,13 \\
Salto Triplo (m) & 12,17 & 0,21 & 15,12 & 0,47 \\
L. Disco (m) & 40,40 & 1,83 & 46,56 & 3,46 \\
L. Dardo (m) & 41,94 & 1,45 & 59,46 & 2,23 \\
L. Martelo (m) & 45,32 & 4,78 & 50,66 & 3,52 \\
A. Peso (m) & 12,91 & 0,75 & 14,85 & 0,64 \\
Marcha 20 km (s) & 8667,83 & 568,21 & 7291,08 & 891,52 \\
Combinadas Hept/Deca (pts) & 4222,50 & 306,75 & 5894,50 & 526,87 \\
\hline
\end{tabular}

Os índices variam de acordo com os resultados de anos anteriores analisados em reunião do conselho técnico e administrativo da CBAt.

Os índices e período para sua obtenção são definidos no início de cada ano através desse mesmo conselho. Entretanto, em virtude da pandemia do coronavírus, o ano de 2020 sofreu algumas modificações como o mês da competição e o período para obtenção dos índices como consta na Tabela 2. 
Tabela 2. Período temporal para obtenção de índices mínimos para o TB

\begin{tabular}{ccccc}
\hline Ano & Data Inicio & Data Fim & Dias & Mês da Competição \\
\hline 2017 & jan/17 & mai/17 & 140 & junho \\
2018 & jan/18 & ago/18 & 213 & setembro \\
2019 & jan/19 & ago/19 & 215 & setembro \\
2020 & jan/19 & nov/20 & 691 & dezembro \\
\hline
\end{tabular}

Como forma de minimizar os efeitos adversos da pandemia e atendendo aos critérios da Organização Mundial de Atletismo (WA) para índices das olímpiadas de Tóquio 2021, o TB foi realizado em dezembro e colocou em seus critérios de participação resultados obtidos desde o mês de janeiro do ano anterior.

Assim, foi possível observar um crescimento no número de participantes do TB como mostra na Tabela 3 abaixo.

Tabela 3. Quantidade de atletas inscritos no TB.

\begin{tabular}{ccccc}
\hline Sexo & & \multicolumn{3}{c}{ Ano } \\
& 2017 & 2018 & 2019 & 2020 \\
\hline Feminino & 259 & 218 & 288 & 386 \\
Masculino & 191 & 185 & 252 & 269 \\
Total & $\mathbf{4 5 0}$ & $\mathbf{4 0 3}$ & $\mathbf{5 4 0}$ & $\mathbf{6 5 5}$ \\
\hline
\end{tabular}

Além dos já mencionados meios para minimizar os efeitos da pandemia, a CBAt estabeleceu que suas federações filiadas que não tiveram estruturas para realizar seus campeonatos estaduais devido à pandemia ganhariam o direito de inscrever mais 5 atletas sem índice mínimo.

Dos mais de dois mil atletas presentes nas últimas edições do TB, foram utilizados para critérios de análise os valores da performance dos atletas finalistas dos anos de 2017 a 2020. Os finalistas em sua maior parte da região Sudeste do Brasil estão demonstrados na Tabela 4. 
Tabela 4. Quantidade de atletas finalistas no TB de 2017 a 2020, por estado

\begin{tabular}{ccccccc}
\hline \multirow{2}{*}{ REGIÃO } & ESTADO & \multicolumn{5}{c}{ ANO } \\
& & 2017 & 2018 & 2018 & 2020 & TOTAL \\
\hline SUDESTE & SP & 235 & 225 & 177 & 158 & 795 \\
$71 \%$ & MG & 6 & 9 & 10 & 11 & 36 \\
& RJ & 17 & 12 & 17 & 10 & 56 \\
& ES & 0 & 0 & 0 & 1 & 1 \\
SUL & SC & 11 & 23 & 35 & 43 & 112 \\
$17 \%$ & PR & 9 & 17 & 21 & 26 & 73 \\
CENTRO- & RS & 6 & 3 & 14 & 10 & 33 \\
OESTE & DF & 5 & 4 & 9 & 12 & 30 \\
$5 \%$ & MT & 8 & 3 & 7 & 9 & 27 \\
NORDESTE & GO & 1 & 0 & 3 & 1 & 5 \\
$5 \%$ & PI & 1 & 3 & 2 & 2 & 8 \\
& PE & 3 & 6 & 11 & 20 & 40 \\
& MA & 0 & 0 & 0 & 9 & 9 \\
& RN & 3 & 1 & 3 & 1 & 8 \\
NORTE & PB & 0 & 0 & 1 & 1 & 2 \\
$1 \%$ & CE & 0 & 0 & 1 & 0 & 1 \\
& TM & 7 & 1 & 1 & 1 & 10 \\
\hline
\end{tabular}

Foi constatada grande participação dos atletas do estado de São Paulo (SP) tornando a região sudeste do Brasil como a de maior expressão do atletismo brasileiro correspondendo a $71 \%$ dos finalistas dos últimos anos.

Para caracterizar melhor a amostra a Tabelas 5 vem apresentar a quantidade de atletas finalistas nos últimos anos separando-os por sexo e a Tabela 6, os dados separados por prova nos anos de 2017 a 2020.

Tabela 5. Quantidade de atletas finalistas no TB de 2017 a 2020 separados por ano e sexo.

\begin{tabular}{cccc}
\hline \multirow{2}{*}{ Ano } & Sexinino & & \\
& 157 & Masculino & Total \\
\hline 2017 & 154 & 155 & $\mathbf{3 1 2}$ \\
2018 & 158 & 153 & $\mathbf{3 0 7}$ \\
2019 & 159 & 154 & $\mathbf{3 1 2}$ \\
2020 & & 156 & $\mathbf{3 1 5}$ \\
\hline
\end{tabular}


Tabela 6. Distribuição dos atletas finalistas nas diferentes provas do TB.

\begin{tabular}{|c|c|c|c|c|c|c|c|c|c|}
\hline \multirow{3}{*}{ PROVAS } & \multicolumn{8}{|c|}{ ANO } & \multirow{3}{*}{ TOTAI } \\
\hline & \multicolumn{2}{|c|}{2017} & \multicolumn{2}{|c|}{2018} & \multicolumn{2}{|c|}{2019} & \multicolumn{2}{|c|}{2020} & \\
\hline & FEM & MAS & FEM & MAS & FEM & MAS & FEM & MAS & \\
\hline $100 \mathrm{~m}$ & 8 & 8 & 8 & 7 & 7 & 7 & 8 & 6 & 59 \\
\hline $200 \mathrm{~m}$ & 7 & 7 & 8 & 7 & 7 & 6 & 8 & 7 & 57 \\
\hline $\begin{array}{c}\text { 110/100 m c/ } \\
\text { Barreira }\end{array}$ & 7 & 7 & 8 & 7 & 8 & 7 & 8 & 8 & 60 \\
\hline $400 \mathrm{~m} \mathrm{c} /$ Barreira & 7 & 8 & 7 & 8 & 8 & 8 & 8 & 8 & 62 \\
\hline $400 \mathrm{~m}$ & 8 & 8 & 8 & 8 & 8 & 7 & 7 & 8 & 62 \\
\hline $800 \mathrm{~m}$ & 8 & 8 & 7 & 8 & 8 & 7 & 8 & 8 & 62 \\
\hline $1500 \mathrm{~m}$ & 8 & 8 & 7 & 8 & 8 & 8 & 8 & 8 & 63 \\
\hline 3000 m Obstáculo & 8 & 8 & 8 & 8 & 8 & 8 & 8 & 8 & 64 \\
\hline $5000 \mathrm{~m}$ & 8 & 7 & 6 & 8 & 8 & 8 & 8 & 8 & 61 \\
\hline $10000 \mathrm{~m}$ & 8 & 8 & 8 & 5 & 8 & 8 & 8 & 8 & 61 \\
\hline Salto distancia & 8 & 8 & 8 & 8 & 8 & 8 & 8 & 8 & 64 \\
\hline Salto altura & 10 & 8 & 7 & 8 & 8 & 8 & 8 & 8 & 65 \\
\hline Salto Vara & 8 & 8 & 8 & 8 & 8 & 8 & 8 & 7 & 63 \\
\hline Salto Triplo & 8 & 8 & 8 & 7 & 8 & 8 & 8 & 8 & 63 \\
\hline L. Disco & 7 & 8 & 8 & 8 & 8 & 8 & 8 & 8 & 63 \\
\hline L. Dardo & 8 & 8 & 8 & 8 & 8 & 8 & 8 & 8 & 64 \\
\hline L. Martelo & 8 & 8 & 8 & 8 & 8 & 8 & 8 & 8 & 64 \\
\hline A. Peso & 7 & 8 & 8 & 8 & 8 & 8 & 8 & 8 & 63 \\
\hline Marcha $20 \mathrm{~km}$ & 8 & 8 & 8 & 8 & 8 & 8 & 8 & 8 & 64 \\
\hline Combinadas & 8 & 6 & 8 & 8 & 8 & 8 & 8 & 8 & 62 \\
\hline Total & 157 & 155 & 154 & 153 & 158 & 154 & 159 & 156 & 1246 \\
\hline
\end{tabular}

Apesar de, por regra, termos de 8 a 12 atletas nas finais, os números de atletas presentes nas finais do TB variaram de 6 a 10 participantes, entretanto ambos os números são devidos a circunstancias próprias, no caso onde ocorreu 6 inscritos era o total de atletas na prova (combinadas decatlo masculino do ano 2017), e no caso onde apresentou 10 finalistas (salto em altura feminino do ano de 2017), ocorreu após 3 atletas ficaram empatadas em 8 lugar na fase final da competição, dando o direito a permanecer na prova. Em geral a presença de 7 atletas na final se torna mais comum quando um determinado atleta ou descumpre regras de partida e é desclassificado, não consegue executar marca válida, ou não completa a prova. 
Tabela 7.Comparação da performance dos atletas do TB em relação a prova, por sexo e ano.

\begin{tabular}{|c|c|c|c|c|c|c|c|c|c|c|c|}
\hline \multirow{2}{*}{ Provas } & \multirow{2}{*}{ Sexo } & \multicolumn{2}{|c|}{2017} & \multicolumn{2}{|c|}{2018} & \multicolumn{2}{|c|}{2019} & \multicolumn{2}{|c|}{2020} & \multirow{2}{*}{ Tam. Efeito } & \multirow{2}{*}{$\mathrm{P}$} \\
\hline & & Média & Des. Padrão & Média & Des. Padrão & Média & Des. Padrão & Média & Des. Padrão & & \\
\hline \multirow{2}{*}{$100 \mathrm{~m} \mathrm{(s)}$} & FEM & 11,46 & 0,18 & 11,53 & 0,20 & 11,45 & 0,12 & 11,62 & 0,20 & 0,143 & 0,237 \\
\hline & MAS & 10,31 & 0,08 & 10,25 & 0,14 & 10,18 & 0,18 & 10,34 & 0,20 & 0,148 & 0,271 \\
\hline \multirow{2}{*}{200 m (s) } & FEM & 23,56 & 0,46 & 23,71 & 0,47 & 24,16 & 0,34 & 24,01 & 0,74 & 0,180 & 0,154 \\
\hline & MAS & 20,78 & 0,38 & 20,61 & 0,21 & 21,00 & 0,30 & 20,62 & 0,19 & 0,265 & 0,065 \\
\hline \multirow{2}{*}{$\begin{array}{l}\text { 100/110 m c/ } \\
\text { Barreiras (s) }\end{array}$} & FEM & 13,73 & 0,27 & 13,72 & 0,22 & 13,58 & 0,22 & 13,89 & 0,53 & 0,114 & 0,343 \\
\hline & MAS & 13,70 & 0,21 & 13,83 & 0,22 & 14,08 & 0,35 & 13,92 & 0,30 & 0,222 & 0,094 \\
\hline \multirow{2}{*}{$\begin{array}{c}400 \mathrm{~m} \mathrm{c} / \\
\text { Barreiras(s) }\end{array}$} & FEM & 58,55 & 1,23 & 59,09 & 1,41 & 59,56 & 2,10 & 61,38 & 6,12 & 0,990 & 0,429 \\
\hline & MAS & 51,03 & 1,44 & 50,35 & 1,40 & 50,33 & 1,27 & 51,45 & 1,35 & 0,121 & 0,298 \\
\hline \multirow{2}{*}{$400 \mathrm{~m}(\mathrm{~s})$} & FEM & 53,88 & 1,13 & 53,88 & 1,40 & 54,20 & 1,06 & 54,42 & 1,44 & 0,035 & 0,804 \\
\hline & MAS & 46,56 & 0,71 & 47,06 & 2,56 & 46,61 & 0,69 & 46,60 & 0,72 & 0,023 & 0,888 \\
\hline \multirow{2}{*}{$800 \mathrm{~m}(\mathrm{~s})$} & FEM & 130,81 & 6,13 & 127,50 & 2,35 & 127,94 & 2,55 & 129,81 & 2,29 & 0,129 & 0,285 \\
\hline & MAS & 108,11 & 1,58 & 109,88 & 2,14 & $110,64^{\mathrm{D}}$ & 2,84 & $107,52^{\mathrm{C}}$ & 0,87 & 0,321 & 0,014 \\
\hline \multirow{2}{*}{$1500 \mathrm{~m}(\mathrm{~s})$} & FEM & $269,27^{\mathrm{C}}$ & 3,36 & $267,11^{\mathrm{C}}$ & 4,73 & $277,62 \mathrm{AB}$ & 7,63 & 272,59 & 7,38 & 0,324 & 0,013 \\
\hline & MAS & $229,57^{\text {В }}$ & 3,05 & $283,47 \mathrm{ACD}$ & 15,36 & 231,22 B & 5,29 & $228,96^{\text {B }}$ & 5,26 & 0,891 & $<\mathbf{0 , 0 0 1}$ \\
\hline \multirow{2}{*}{3000 m Obst. (s) } & FEM & 680,16 & 43,85 & 670,56 & 54,23 & 669,84 & 35,45 & 663,91 & 42,20 & 0,019 & 0,907 \\
\hline & MAS & 539,49 & 15,11 & 542,04 & 14,23 & 553,98 & 22,74 & 544,59 & 17,03 & 0,100 & 0,393 \\
\hline \multirow{2}{*}{$5000 \mathrm{~m}(\mathrm{~s})$} & FEM & 1006,63 & 16,24 & 1028,77 & 25,78 & 1019,47 & 25,02 & 1017,10 & 26,83 & 0,106 & 0,394 \\
\hline & MAS & 874,00 & 30,97 & 872,44 & 9,62 & 870,01 & 16,93 & 864,56 & 12,14 & 0,040 & 0,770 \\
\hline \multirow{2}{*}{10000 m (s) } & FEM & $2087,25^{\mathrm{D}}$ & 38,82 & $2123,13^{\mathrm{D}}$ & 61,55 & $2116,96^{\mathrm{D}}$ & 47,85 & 2205,23 АВC & 81,85 & 0,380 & $\mathbf{0 , 0 0 3}$ \\
\hline & MAS & 1791,68 & 27,66 & 1798,35 & 46,90 & 1815,36 & 23,69 & 1813,05 & 28,63 & 0,112 & 0,386 \\
\hline
\end{tabular}

Leg.: Diferenças significativas: A - em relação a 2017; B - em relação a 2018; C - em relação a 2019; D - em relação a 2020 
Tabela 7. Comparação da performance dos atletas do TB em relação a prova, por sexo e ano. (continuação)

\begin{tabular}{|c|c|c|c|c|c|c|c|c|c|c|c|}
\hline \multirow[b]{2}{*}{ Provas } & \multirow[b]{2}{*}{ Sexo } & \multicolumn{2}{|c|}{2017} & \multicolumn{2}{|c|}{2018} & \multicolumn{2}{|c|}{2019} & \multicolumn{2}{|c|}{2020} & \multirow{2}{*}{ Tam. Efeito. } & \multirow{2}{*}{$\mathrm{P}$} \\
\hline & & Média & Des. Padrão & Média & $\begin{array}{c}\text { Des. } \\
\text { Padrão }\end{array}$ & Média & Des. Padrão & Média & Des. Padrão & & \\
\hline \multirow{2}{*}{$\begin{array}{l}\text { Salto em Distância } \\
(\mathrm{m})\end{array}$} & FEM & 6,22 & 0,28 & 6,17 & 0,24 & 6,10 & 0,18 & 6,20 & 0,23 & 0,043 & 0,741 \\
\hline & MAS & 7,62 & 0,11 & 7,80 & 0,31 & 7,53 & 0,10 & 7,67 & 0,26 & 0,189 & 0,112 \\
\hline \multirow{2}{*}{$\begin{array}{l}\text { Salto em Altura } \\
(\mathrm{m})\end{array}$} & FEM & $1,68^{\text {B }}$ & 0,07 & $1,77^{\mathrm{A}}$ & 0,40 & 1,76 & 0,06 & 1,70 & 0,07 & 0,290 & 0,018 \\
\hline & MAS & 2,13 & 0,07 & 2,14 & 0,07 & 2,13 & 0,06 & 2,14 & 0,09 & 0,010 & 0,962 \\
\hline \multirow{2}{*}{ Salto com Vara (m) } & FEM & 3,88 & 0,23 & 3,94 & 0,28 & 3,82 & 0,32 & 3,78 & 0,22 & 0,061 & 0,615 \\
\hline & MAS & 5,22 & 0,26 & 5,07 & 0,36 & 4,89 & 0,48 & 4,79 & 0,38 & 0,177 & 0,147 \\
\hline \multirow{2}{*}{ Salto Triplo (m) } & FEM & 13,40 & 0,64 & 13,26 & 0,30 & 13,04 & 0,47 & 13,16 & 0,61 & 0,068 & 0,569 \\
\hline & MAS & 15,86 & 0,43 & 15,77 & 0,69 & 15,97 & 0,68 & 15,78 & 0,55 & 0,019 & 0,912 \\
\hline \multirow{2}{*}{ L. Disco (m) } & FEM & 49,07 & 7,55 & 53,34 & 8,77 & 50,76 & 7,93 & 51,52 & 7,47 & 0,040 & 0,773 \\
\hline & MAS & 53,85 & 3,01 & 53,35 & 2,88 & 52,60 & 4,15 & 52,00 & 3,67 & 0,045 & 0,724 \\
\hline \multirow{2}{*}{ L. Dardo (m) } & FEM & 55,14 & 4,22 & 50,52 & 5,18 & 49,92 & 6,93 & 51,75 & 6,03 & 0,126 & 0,278 \\
\hline & MAS & 70,75 & 3,90 & 68,76 & 3,60 & 66,59 & 4,19 & 64,46 & 10,09 & 0,146 & 0,212 \\
\hline \multirow{2}{*}{ L. Martelo (m) } & FEM & 57,41 & 4,74 & 56,23 & 4,99 & 51,26 & 4,06 & 54,65 & 4,85 & 0,219 & 0,071 \\
\hline & MAS & 64,66 & 5,87 & 65,18 & 5,51 & 60,50 & 7,80 & 59,69 & 6,14 & 0,143 & 0,223 \\
\hline \multirow{2}{*}{ A. Peso (m) } & FEM & 15,62 & 1,72 & 15,17 & 1,62 & 15,44 & 1,46 & 14,66 & 2,23 & 0,045 & 0,737 \\
\hline & MAS & 18,29 & 1,44 & 18,46 & 2,04 & 17,27 & 2,57 & 17,41 & 2,22 & 0,066 & 0,585 \\
\hline \multirow{2}{*}{ Marcha 20 km (s) } & FEM & 6468,50 & 558,43 & $7069,63^{\mathrm{D}}$ & 416,25 & 6650,63 & 416,63 & $6265,24^{\mathrm{B}}$ & 421,30 & 0,325 & $\mathbf{0 , 0 1 1}$ \\
\hline & MAS & 5492,50 & 368,33 & 5856,00 & 499,10 & 5642,50 & 376,37 & 6195,56 & 923,86 & 0,188 & 0,116 \\
\hline \multirow{2}{*}{$\begin{array}{c}\text { Combinadas } \\
\text { Hept/Deca (pts) }\end{array}$} & FEM & 5441,75 & 402,39 & 5308,13 & 571,79 & 5288,00 & 297,87 & 51121,75 & 442,00 & 0,071 & 0,552 \\
\hline & MAS & 7116,00 & 554,51 & 6963,00 & 329,81 & 6995,13 & 782,80 & 6785,00 & 1217,68 & 0,023 & 0,892 \\
\hline
\end{tabular}

Leg.: Diferenças significativas: A - em relação a 2017; B - em relação a 2018; C - em relação a 2019; D - em relação a 2020 
De acordo com a Tabela 7 conseguimos observar algumas diferenças anuais da performance dos atletas finalistas do TB. Muitas dessas, apesar de aumento ou diminuição das médias de seus valores, não apresentaram diferenças significativas, como foi o caso das provas de velocidade, lançamentos e arremesso, e alguns saltos além das combinadas. Já provas de meio fundo e fundo, e o salto em altura apresentaram diferenças de performance entre os anos 2017 a 2020.

Os resultados apresentaram diferenças significativas em 6 provas, sendo 4 de categoria feminina e 2 de categoria masculina. Entretanto somente uma prova $(10000 \mathrm{~m}$ feminino) foi constatada a diferença significativa da performance do ano 2020 com tempo superior aos demais.

Duas provas masculinas do ano de 2020 apresentaram diferenças em relação aos anos anteriores, os $800 \mathrm{~m}$ e os $1500 \mathrm{~m}$. Esta diferença foi considerando um desempenho melhor no ano de 2020, com o tempo de realização da prova menor que nos anos anteriores. $\mathrm{O}$ mesmo ocorreu na prova de $20 \mathrm{~km}$ marcha atlética feminina. Isso demonstra que apesar dos fatores adversos durante os treinos e competições do ano de 2020, não influenciaram no desempenho destas provas.

Os resultados da Tabela 7 estão representados visualmente nas Figuras de 1 a 20:

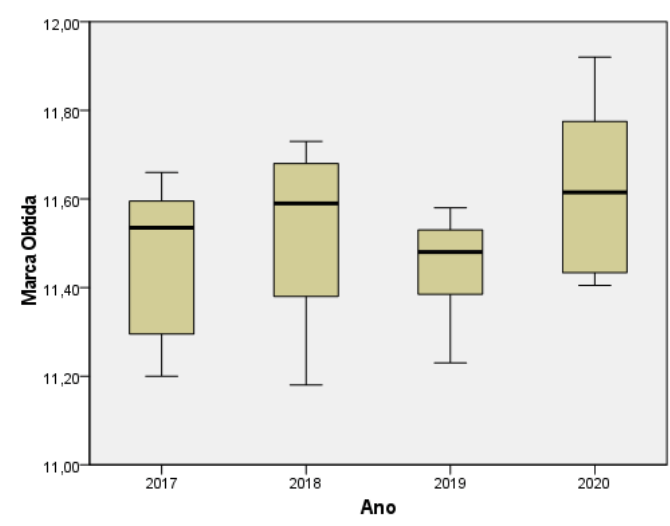

$$
\mathrm{P}=0,237
$$

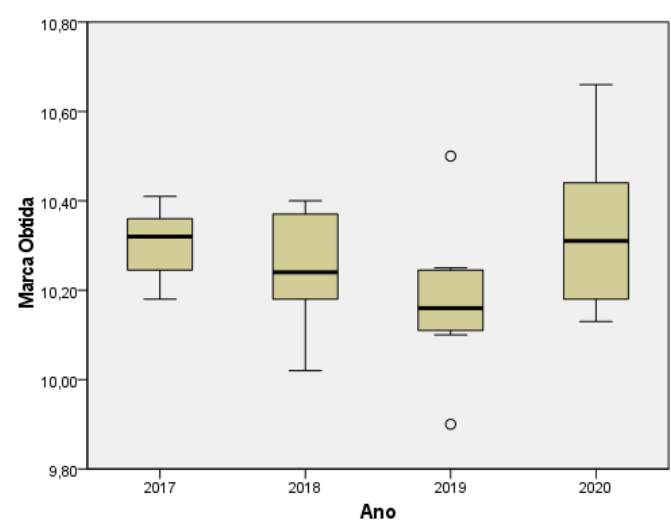

$\mathrm{P}=0,271$

Figura 1. Resultados dos finalistas dos $100 \mathrm{~m}$ rasos feminino (painel da esquerda) e masculino (painel da direita), nos anos de 2017-2020 

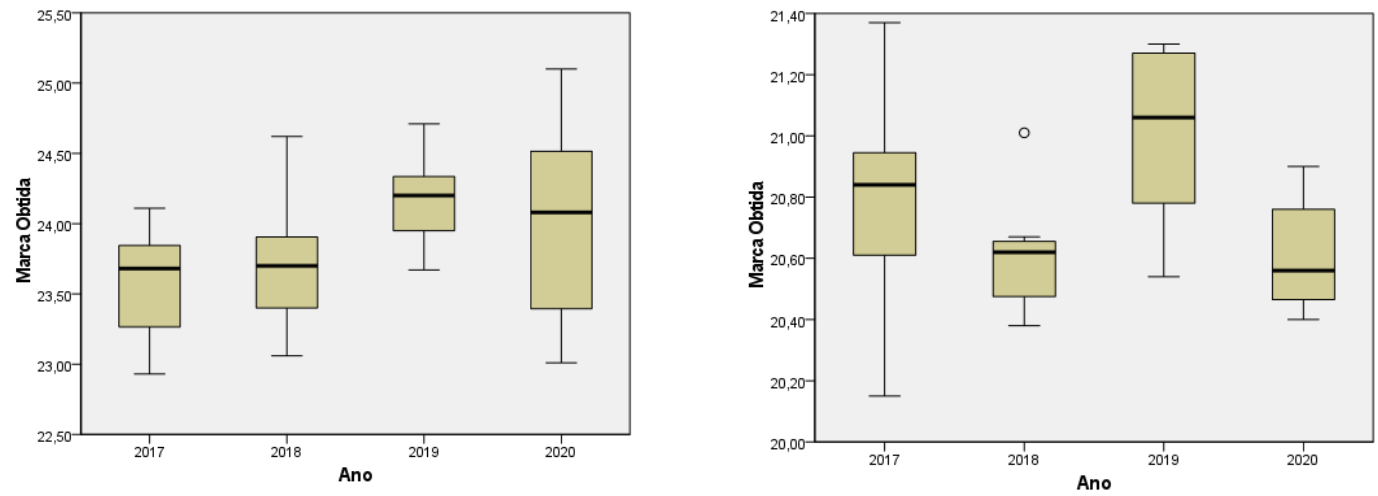

$P=0,154$

$$
P=0,065
$$

Figura 2. Resultados dos finalistas dos $200 \mathrm{~m}$ rasos feminino (painel da esquerda) e masculino (painel da direita), nos anos de 2017-2020

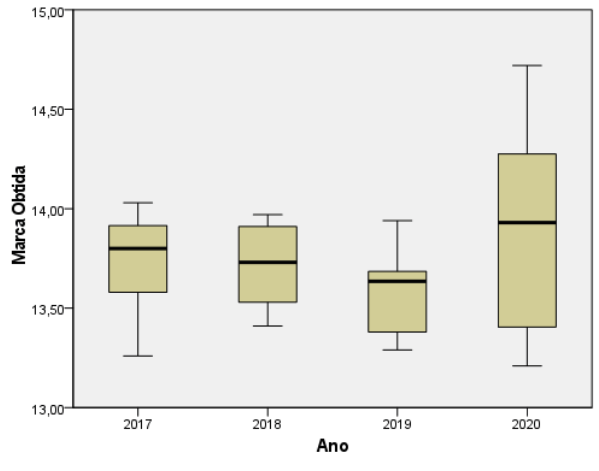

$\mathrm{P}=0,343$

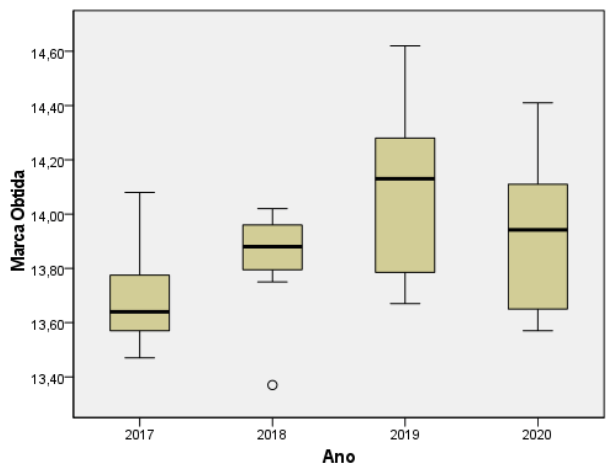

$\mathrm{P}=0,094$

Figura 3. Resultados dos finalistas dos $100 / 110 \mathrm{~m}$ com barreiras feminino (painel da esquerda) e masculino (painel da direita), nos anos de 2017-2020

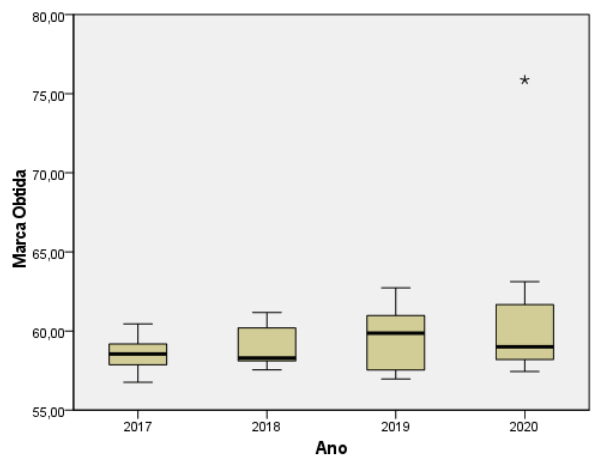

$$
\mathrm{P}=0,429
$$

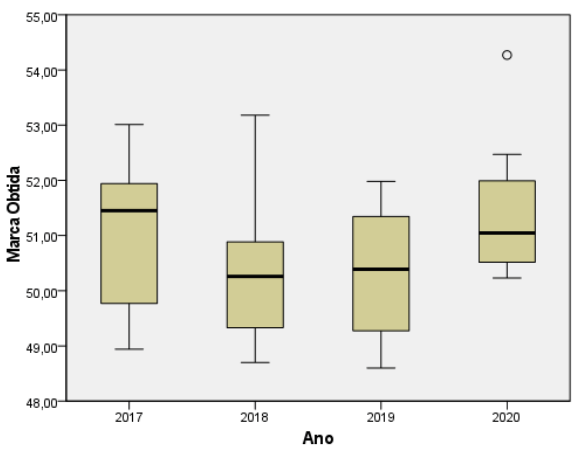

$\mathrm{P}=0,298$

Figura 4. Resultados dos finalistas dos $400 \mathrm{~m}$ com barreiras feminino (painel da esquerda) e masculino (painel da direita), nos anos de 2017-2020 


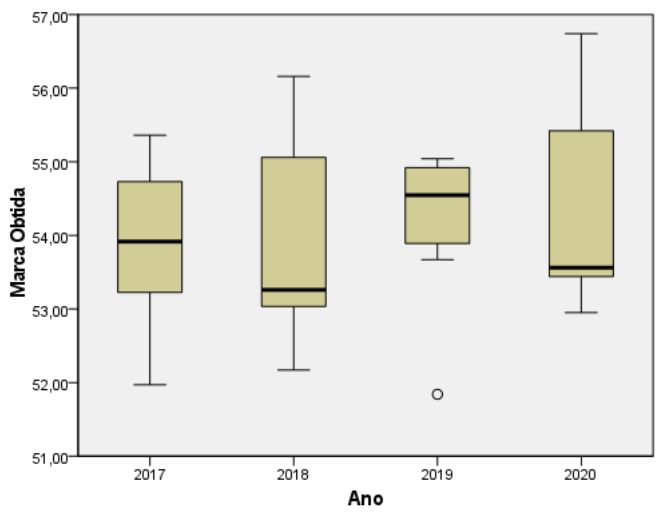

$\mathrm{P}=0,804$

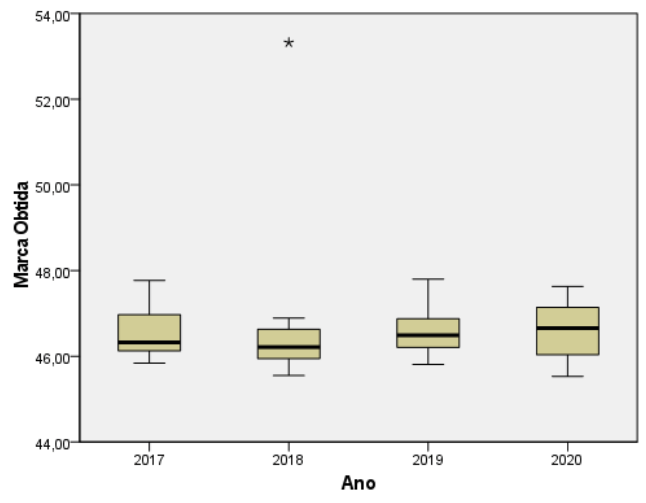

$\mathrm{P}=0,888$

Figura 5. Resultados dos finalistas dos $400 \mathrm{~m}$ feminino (painel da esquerda) e masculino (painel da direita), nos anos de 2017-2020

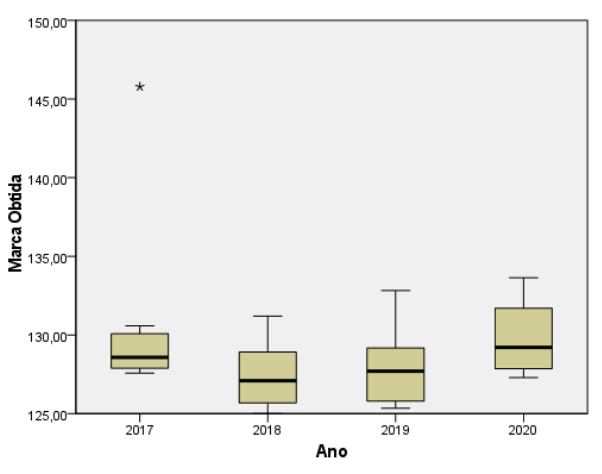

$\mathrm{P}=0,285$

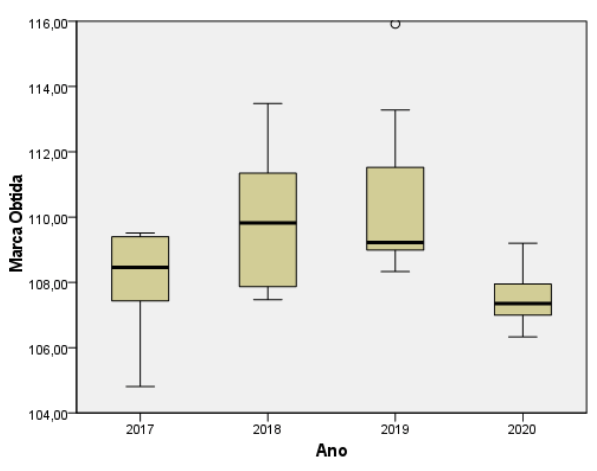

$\mathrm{P}=0,014$

Figura 6. Resultados dos finalistas dos $800 \mathrm{~m}$ feminino (painel da esquerda) e masculino (painel da direita), nos anos de 2017-2020

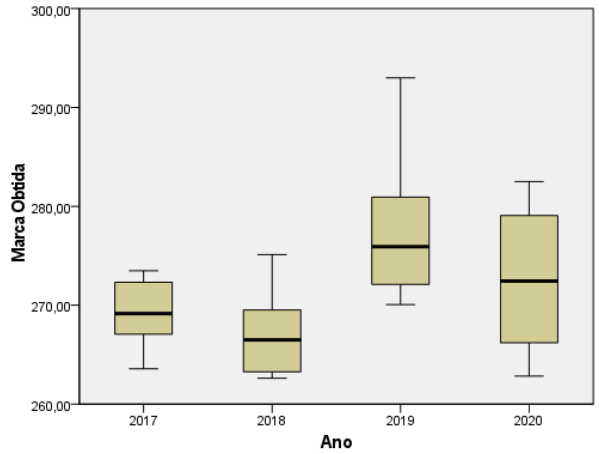

$$
\mathrm{P}=0,013
$$

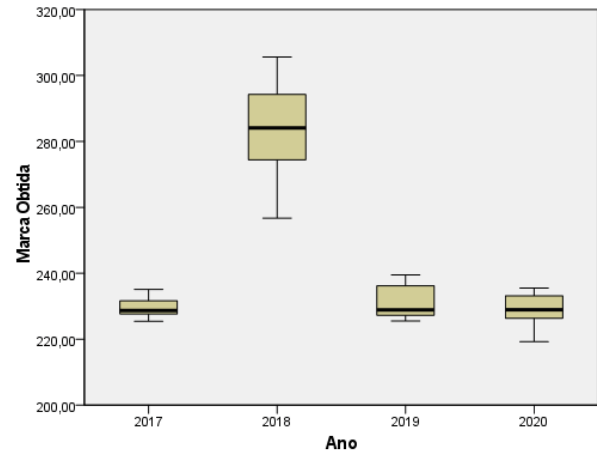

$\mathrm{P}<0,001$

Figura 7. Resultados dos finalistas dos $1500 \mathrm{~m}$ feminino (painel da esquerda) e masculino (painel da direita), nos anos de 2017-2020 


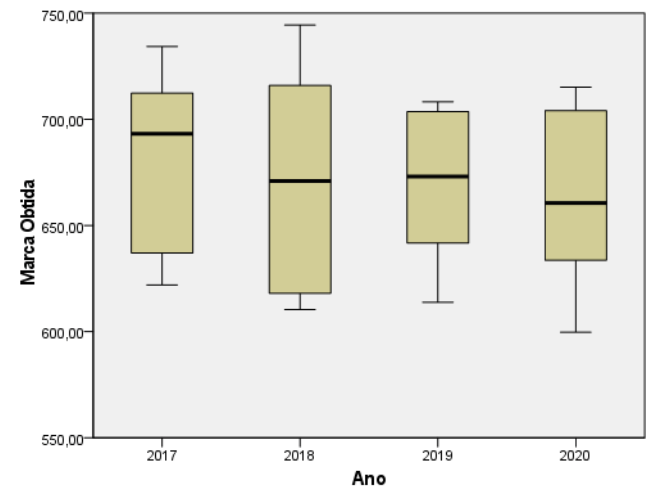

$$
\mathrm{P}=0,907
$$

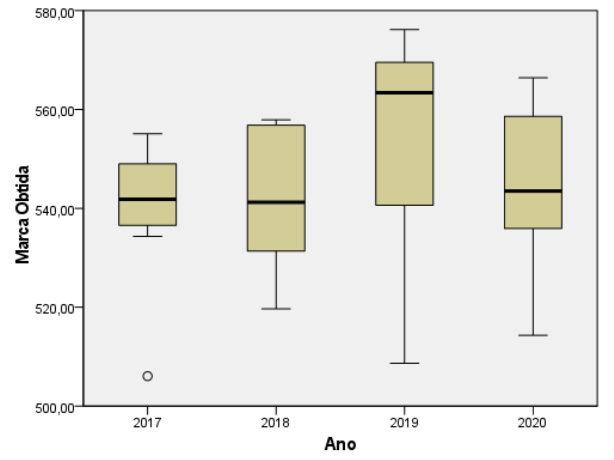

$\mathrm{P}=0,393$

Figura 8. Resultados dos finalistas dos 3000 m Obst. feminino (painel da esquerda) e masculino (painel da direita), nos anos de 2017-2020

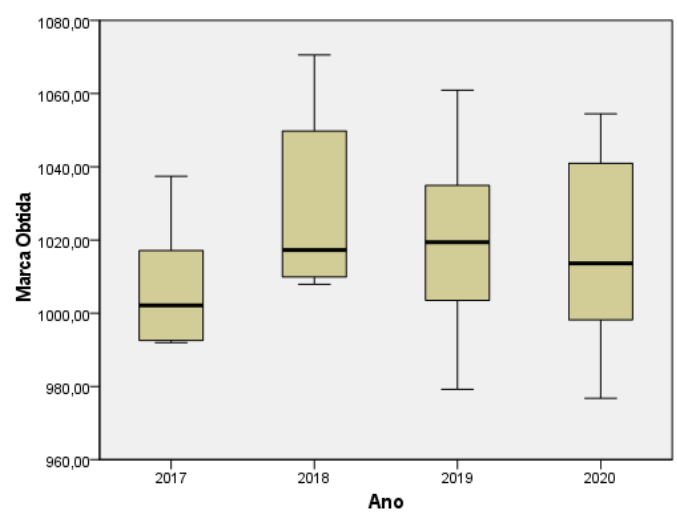

$\mathrm{P}=0,394$

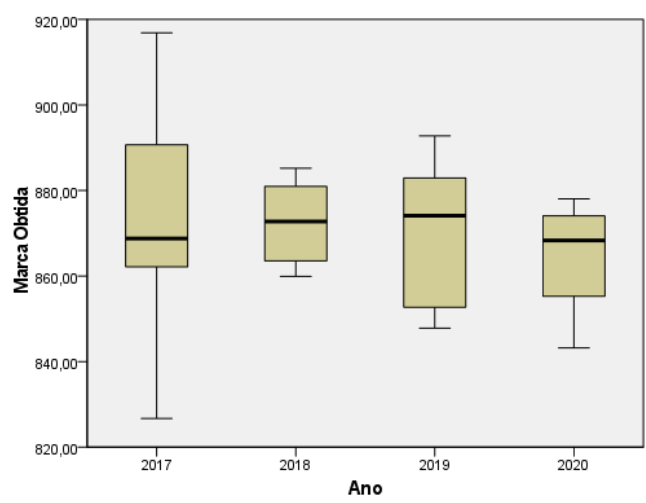

$\mathrm{P}=0,770$

Figura 9. Resultados dos finalistas dos $5000 \mathrm{~m}$ feminino (painel da esquerda) e masculino (painel da direita), nos anos de 2017-2020

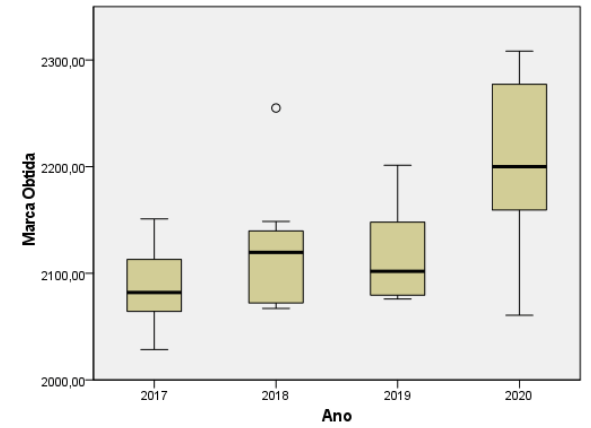

$\mathrm{P}=0,003$

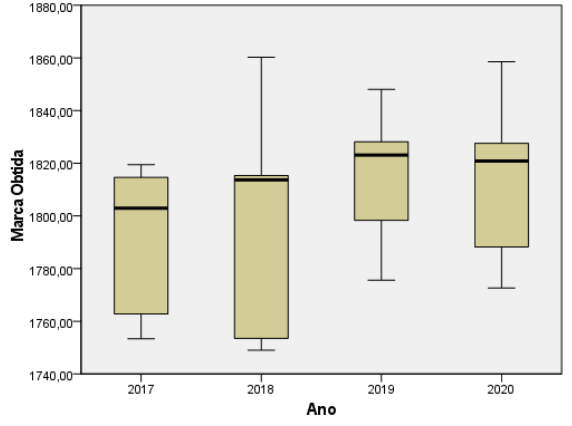

$\mathrm{P}=0,386$

Figura 10. Resultados dos finalistas dos $10000 \mathrm{~m}$ feminino (painel da esquerda) e masculino (painel da direita), nos anos de 2017-2020 

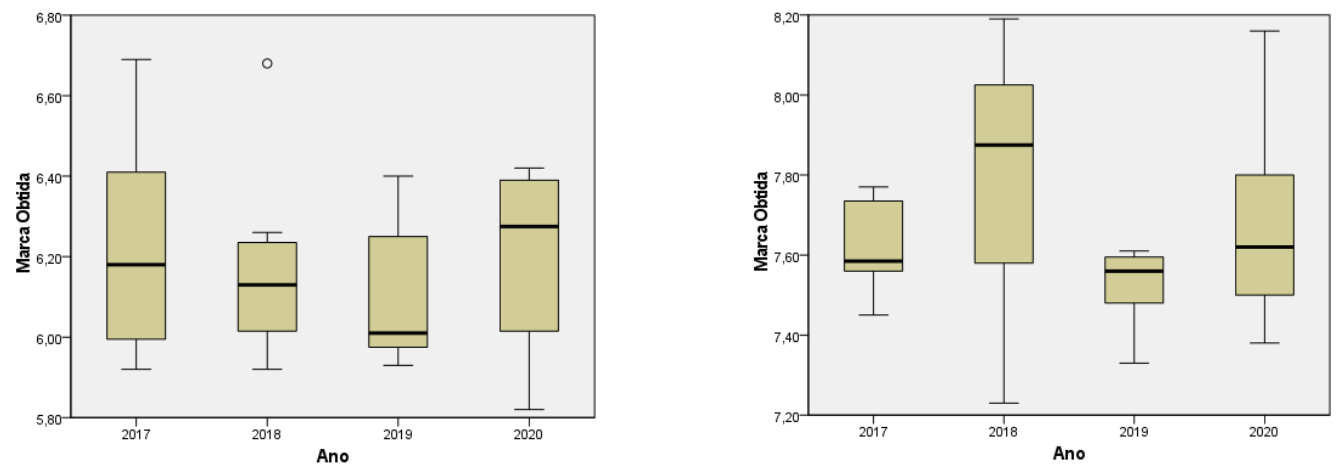

$\mathrm{P}=0,741$

$\mathrm{P}=0,112$

Figura 11. Resultados dos finalistas do salto em distância feminino (painel da esquerda) e masculino (painel da direita), nos anos de 2017-2020

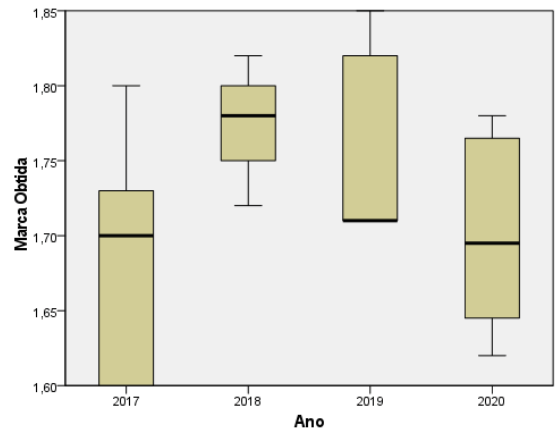

$\mathrm{P}=0,018$

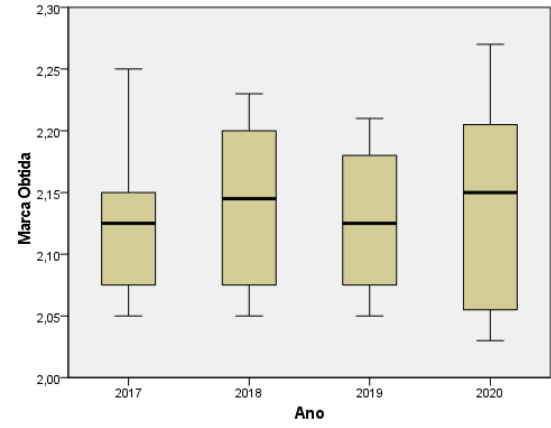

$\mathrm{P}=0,962$

Figura 12. Resultados dos finalistas do salto em altura feminino (painel da esquerda) e masculino (painel da direita), nos anos de 2017-2020

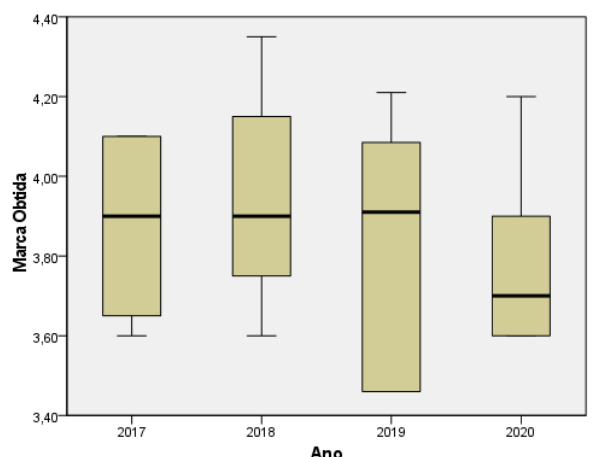

$\mathrm{P}=0,625$

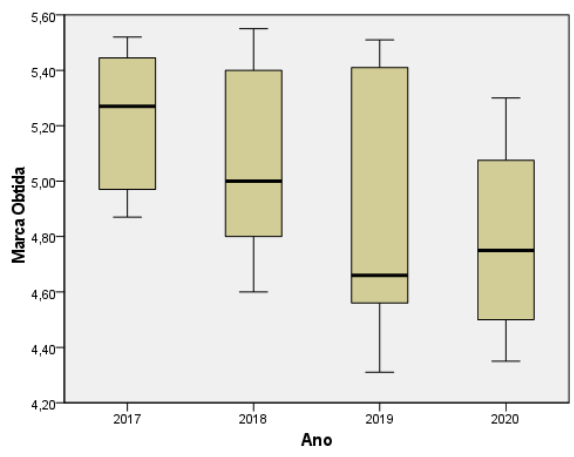

$\mathrm{P}=0,147$

Figura 13. Resultados dos finalistas do salto com vara feminino (painel da esquerda) e masculino (painel da direita), nos anos de 2017-2020 

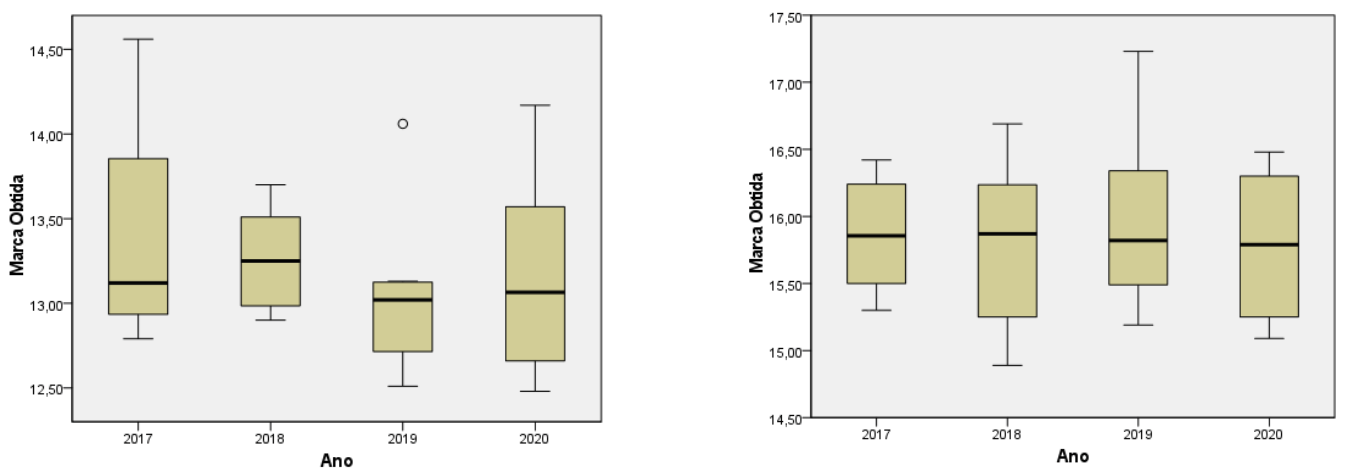

$\mathrm{P}=0,569$

$\mathrm{P}=0,912$

Figura 14. Resultados dos finalistas do salto triplo feminino (painel da esquerda) e masculino (painel da direita), nos anos de 2017-2020

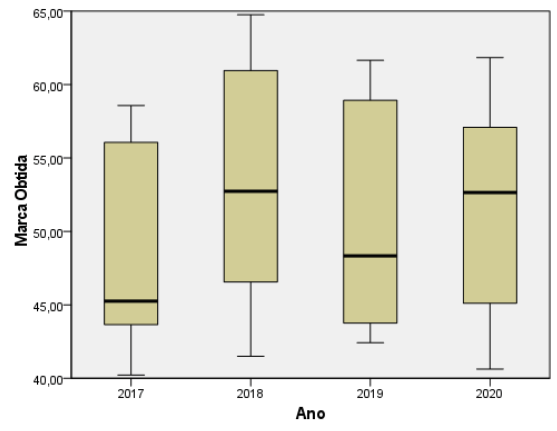

$\mathrm{P}=0,773$

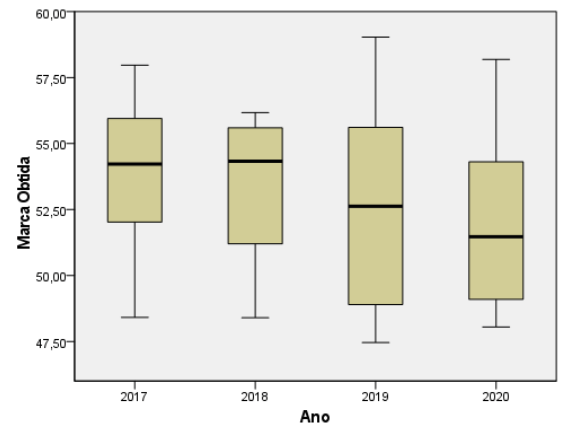

$\mathrm{P}=724$

Figura 15. Resultados dos finalistas do lançamento do disco feminino (painel da esquerda) e masculino (painel da direita), nos anos de 2017-2020

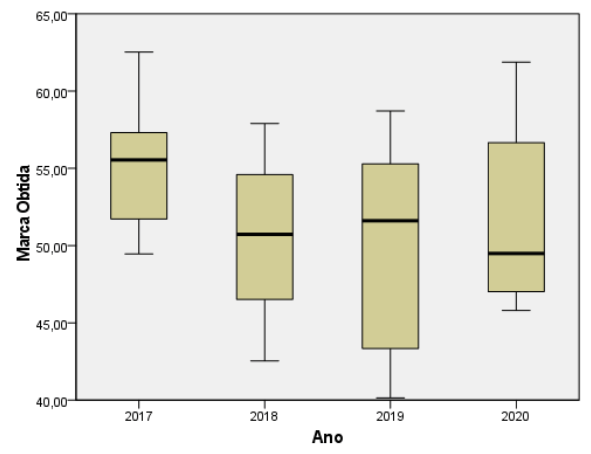

$\mathrm{P}=0,278$

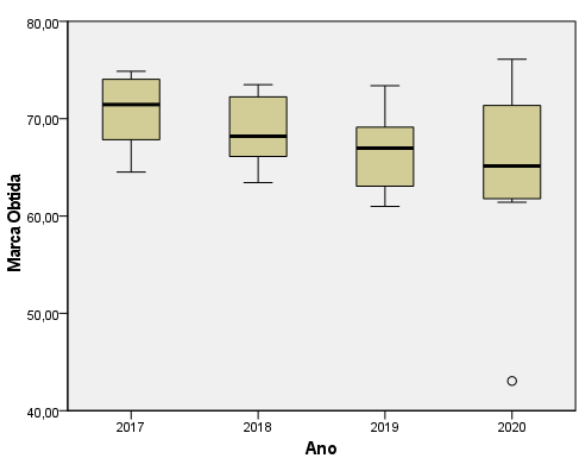

$\mathrm{P}=0,212$

Figura 16. Resultados dos finalistas do lançamento do dardo feminino (painel da esquerda) e masculino (painel da direita), nos anos de 2017-2020 


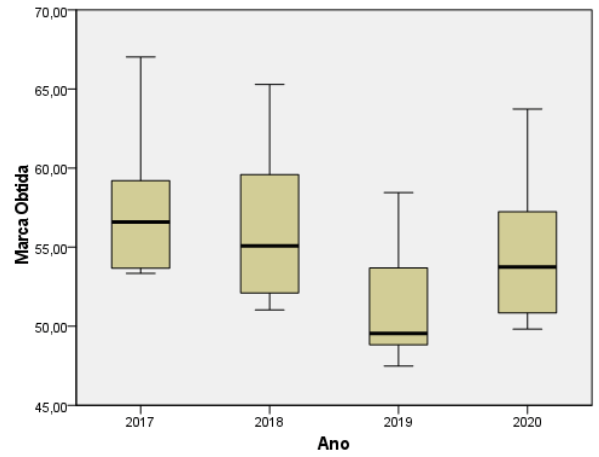

$\mathrm{P}=0,071$

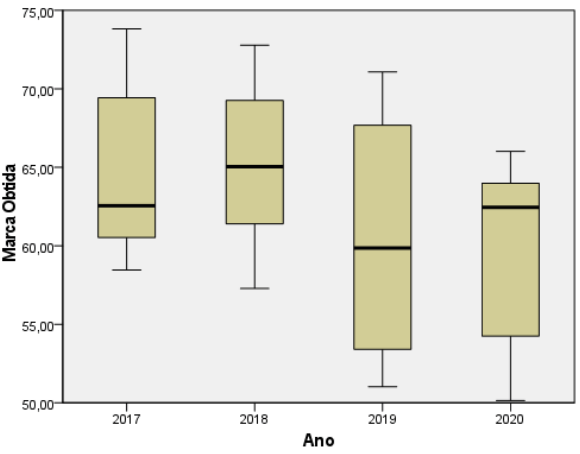

$\mathrm{P}=0,223$

Figura 17. Resultados dos finalistas do lançamento do martelo feminino (painel da esquerda) e masculino (painel da direita), nos anos de 2017-2020

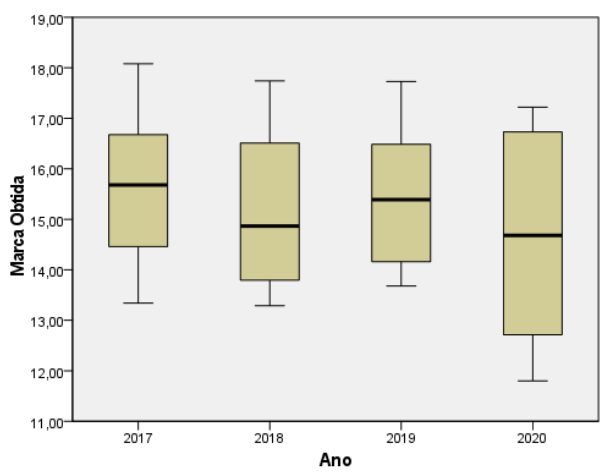

$$
\mathrm{P}=0,737
$$

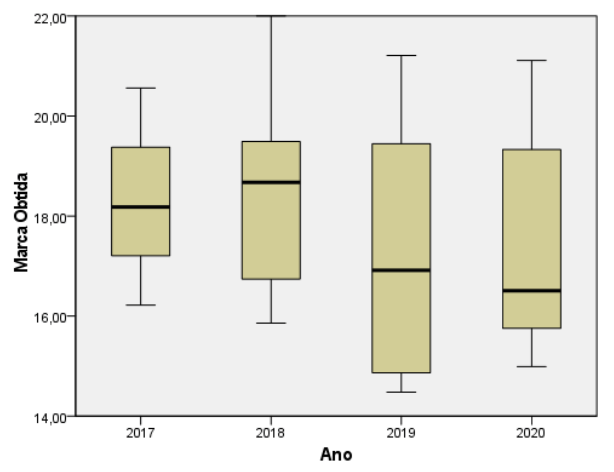

$\mathrm{P}=0,585$

Figura 18. Resultados dos finalistas do arremesso do peso feminino (painel da esquerda) e masculino (painel da direita), nos anos de 2017-2020

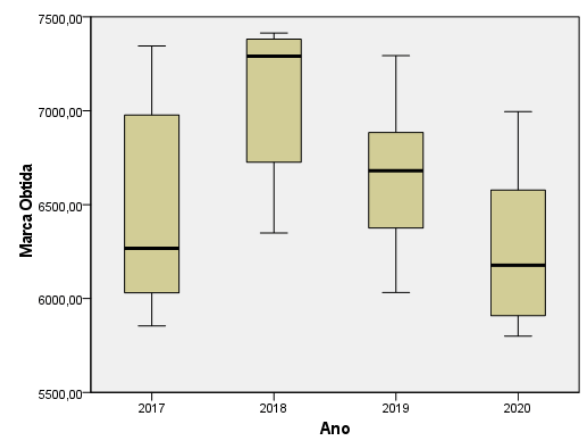

$\mathrm{P}=0,011$

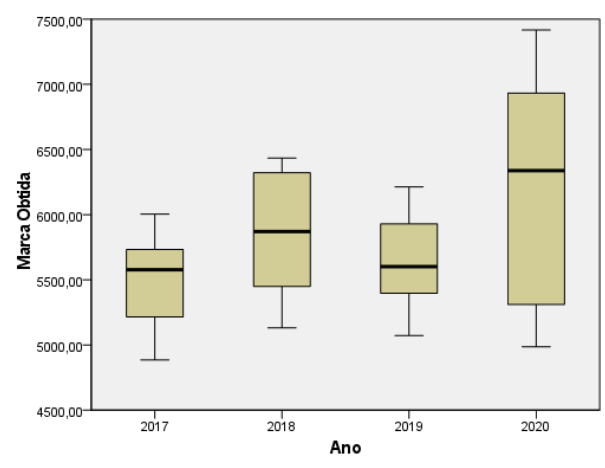

$\mathrm{P}=0,116$

Figura 19. Resultados dos finalistas dos $20 \mathrm{~km}$ em marcha atlética feminino (painel da esquerda) e masculino (painel da direita), nos anos de 2017-2020 

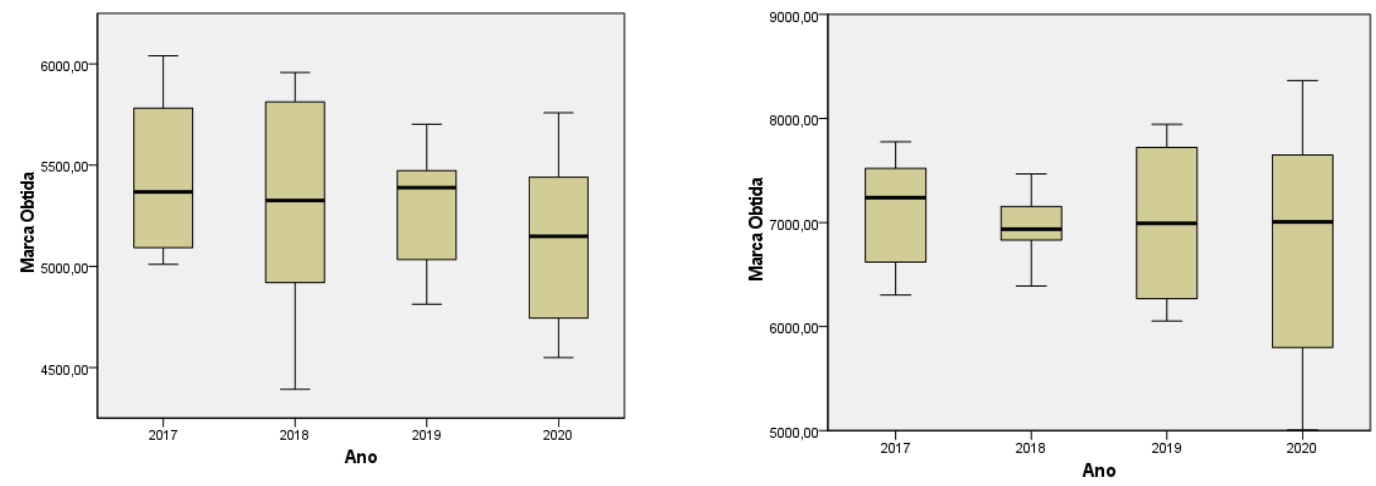

$\mathrm{P}=0,552$

$\mathrm{P}=0,892$

Figura 20. Resultados dos finalistas das combinadas: heptatlo feminino (painel da esquerda) e decatlo masculino (painel da direita), nos anos de 2017-2020

De acordo com os resultados o ano de 2020 não apresentou diferenças estatísticas relevantes comparado aos anos de 2017-2019, apresentando somente 1 (uma) prova das 40 (quarenta) provas analisadas teve como foco o ano 2020: $10.000 \mathrm{~m}$ feminino.

Há que se observar que as atletas participantes do $10.000 \mathrm{~m}$ feminino, foram, em maioria, as mesmas atletas da prova dos $5.000 \mathrm{~m}$, e nesta prova não apresentou diferenças estatísticas sobre o resultado. Apesar de ser comum este tipo de prática, um atleta participar de mais de uma prova, o que pode ter ocorrido para explicar tal fato seria o tempo de intervalo entre as provas dos $5.000 \mathrm{~m}$ para a prova dos $10.000 \mathrm{~m}$, onde talvez este tempo pudesse ser curto para que as atletas obtivessem uma recuperação adequada.

Ainda que os resultados fossem de não apresentar diferenças, quisemos observar se os resultados seriam mais sensíveis quando analisarmos os resultados agrupando-os por colocação, portanto dividimos os resultados por ordem de classificação na competição, desse modo, analisamos os resultados dos medalhistas e os não medalhistas para observar tal efeito. O resultado desta análise pode ser observado na Tabela 8. 
Tabela 8. Comparação entre os últimos medalhistas e não medalhistas do TB separado por sexo, prova e ano.

\begin{tabular}{|c|c|c|c|c|c|c|c|c|c|c|c|c|c|}
\hline \multirow{3}{*}{ Provas } & \multirow{3}{*}{ Ano } & \multicolumn{5}{|c|}{ Feminino } & \multicolumn{6}{|c|}{ Masculino } & \multirow[b]{3}{*}{$P$} \\
\hline & & \multicolumn{3}{|c|}{ Medalhistas } & \multicolumn{2}{|c|}{ Não Medalhistas } & \multicolumn{4}{|c|}{ Medalhistas } & \multicolumn{2}{|c|}{ Não Medalhistas } & \\
\hline & & Média & $\mathrm{DP}$ & $P$ & Média & DP & $P$ & Média & DP & $P$ & Média & $\mathrm{DP}$ & \\
\hline \multirow{4}{*}{$100 \mathrm{~m}$} & 2017 & 11,263 & 0,078 & \multirow{4}{*}{0,377} & 11,584 & 0,065 & \multirow{4}{*}{0,017} & 10,223 & 0,045 & \multirow{4}{*}{0,121} & 10,354 & 0,043 & \multirow{4}{*}{0,144} \\
\hline & 2018 & 11,313 & 0,174 & & $11,654^{\mathrm{D}}$ & 0,062 & & 10,127 & 0,093 & & 10,345 & 0,072 & \\
\hline & 2019 & 11,333 & 0,093 & & 11,630 & 0,042 & & 10,040 & 0,122 & & 10,288 & 0,147 & \\
\hline & 2020 & 11,424 & 0,311 & & $11,740^{\mathrm{B}}$ & 0,145 & & 10,187 & 0,060 & & 10,490 & 0,151 & \\
\hline \multirow{4}{*}{$200 \mathrm{~m}$} & 2017 & 23,153 & 0,370 & \multirow{4}{*}{0,080} & 23,870 & 0,201 & \multirow{4}{*}{0,059} & 20,457 & 0,266 & \multirow{4}{*}{0,149} & 21,025 & 0,235 & \multirow{4}{*}{0,007} \\
\hline & 2018 & 23,287 & 0,197 & & 23,966 & 0,387 & & 20,443 & 0,057 & & $20,735^{c}$ & 0,184 & \\
\hline & 2019 & 23,857 & 0,169 & & 24,395 & 0,230 & & 20,750 & 0,197 & & $21,253^{\mathrm{BD}}$ & 0,057 & \\
\hline & 2020 & 23,267 & 0,402 & & 24,458 & 0,470 & & 20,443 & 0,067 & & $20,745^{c}$ & 0,140 & \\
\hline \multirow{4}{*}{$100 / 110 \mathrm{~m}$} & 2017 & 13,473 & 0,185 & \multirow{4}{*}{0,381} & 13,915 & 0,122 & \multirow{4}{*}{0,011} & 13,537 & 0,833 & \multirow{4}{*}{0,418} & $13,817^{c}$ & 0,188 & \multirow{4}{*}{0,011} \\
\hline & 2018 & 13,490 & 0,086 & & 13,850 & 0,138 & & 13,653 & 0,249 & & 13,955 & 0,058 & \\
\hline & 2019 & 13,350 & 0,079 & & $13,716^{D}$ & 0,130 & & 13,747 & 0,116 & & $14,327^{A}$ & 0,223 & \\
\hline & 2020 & 13,340 & 0,130 & & $14,226^{C}$ & 0,347 & & 13,623 & 0,047 & & 14,103 & 0,210 & \\
\hline \multirow{4}{*}{$400 \mathrm{~m} \mathrm{c} / \mathrm{Bar}$} & 2017 & 57,497 & 0,772 & \multirow{4}{*}{0,435} & 59,343 & 0,830 & \multirow{4}{*}{0,438} & 49,493 & 0,800 & \multirow{4}{*}{0,074} & 51,958 & 0,310 & \multirow{4}{*}{0,317} \\
\hline & 2018 & 57,923 & 0,361 & & 59,963 & 1,222 & & 49,120 & 0,394 & & 51,094 & 1,230 & \\
\hline & 2019 & 57,350 & 0,362 & & 60,884 & 1,343 & & 49,050 & 0,762 & & 51,090 & 0,763 & \\
\hline & 2020 & 57,947 & 0,467 & & 63,440 & 7,162 & & 50,420 & 0,168 & & 52,068 & 1,375 & \\
\hline \multirow{4}{*}{$400 \mathrm{~m}$} & 2017 & 52,807 & 0,790 & \multirow{4}{*}{0,779} & 54,530 & 0,730 & & 46,030 & 0,171 & & 46,872 & 0,733 & \\
\hline & 2018 & 52,747 & 0,499 & & 54,560 & 1,321 & 0666 & 45,813 & 0,270 & 0670 & 47,802 & 3,098 & \\
\hline & 2019 & 53,207 & 1,204 & & 54,794 & 0,233 & 0,666 & 46,073 & 0,350 & $0,6 / 8$ & 47,010 & 0,598 & 0,819 \\
\hline & 2020 & 53,277 & 0,284 & & 55,285 & 1,340 & & 45,867 & 0,368 & & 47,044 & 0,423 & \\
\hline
\end{tabular}

Leg.: ${ }^{\mathrm{A}}$ Diferença em relação a 2017; ${ }^{\mathrm{B}}$ Diferença em relação a 2018; ${ }^{\mathrm{C}}$ Diferença em relação a 2019; ${ }^{\mathrm{D}}$ Diferença em relação a 2020 
Tabela 8. Comparação entre os últimos medalhistas e não medalhistas do TB separado por sexo, prova e ano

\begin{tabular}{|c|c|c|c|c|c|c|c|c|c|c|c|c|c|}
\hline \multirow{3}{*}{ Provas } & \multirow{3}{*}{ Ano } & \multicolumn{5}{|c|}{ Feminino } & \multicolumn{7}{|c|}{ Masculino } \\
\hline & & \multicolumn{2}{|c|}{ Medalhistas } & \multicolumn{3}{|c|}{ Não Medalhistas } & \multicolumn{3}{|c|}{ Medalhistas } & \multicolumn{3}{|c|}{ Não Medalhistas } & \multirow[b]{2}{*}{$\mathrm{P}$} \\
\hline & & Média & DP & $\mathrm{P}$ & Média & DP & $\mathrm{P}$ & Média & DP & $\mathrm{P}$ & Média & DP & \\
\hline \multirow{4}{*}{$800 \mathrm{~m}$} & 2017 & $127,783^{\mathrm{BC}}$ & 0,311 & \multirow{4}{*}{0,001} & 132,620 & 7,405 & \multirow{4}{*}{0,538} & $106,56^{\mathrm{C}}$ & 1,539 & \multirow{4}{*}{0,042} & 109,046 & 0,559 & \multirow{4}{*}{0,009} \\
\hline & 2018 & $125,453 \mathrm{AD}$ & 0,605 & & 129,030 & 1,876 & & 17,737 & 0,265 & & $111,162^{\mathrm{D}}$ & 1,577 & \\
\hline & 2019 & $125,643 \mathrm{AD}$ & 0,366 & & 129,312 & 2,238 & & $108,77^{\mathrm{A}}$ & 0,440 & & $112,047^{\mathrm{D}}$ & 3,146 & \\
\hline & 2020 & $127,666^{\mathrm{BC}}$ & 0,396 & & 131,092 & 1,898 & & 106,773 & 0,404 & & $107,96^{\mathrm{BC}}$ & 0,767 & \\
\hline \multirow{4}{*}{$1500 \mathrm{~m}$} & 2017 & $265,91^{\mathrm{C}}$ & 2,019 & \multirow{4}{*}{0,002} & $271,28^{\mathrm{C}}$ & 2,047 & \multirow{4}{*}{0,013} & $226,91^{\text {В }}$ & 1,294 & \multirow{4}{*}{0,001} & $231,16^{\mathrm{B}}$ & 2,643 & \multirow{4}{*}{0,001} \\
\hline & 2018 & $263,05^{\mathrm{C}}$ & 0,736 & & $270,16^{\mathrm{C}}$ & 3,926 & & $268,56 \mathrm{ACD}$ & 10,964 & & 292,44 ACD & 9,183 & \\
\hline & 2019 & $271,43 \mathrm{ABD}$ & 1,244 & & $281,33^{\mathrm{AB}}$ & 7,418 & & $226,68^{\text {B }}$ & 1,059 & & $233,93^{\text {в }}$ & 4,875 & \\
\hline & 2020 & $265,08^{\mathrm{C}}$ & 2,396 & & 277,00 & 4,982 & & $223,98^{\text {в }}$ & 4,114 & & $231,94^{\mathrm{B}}$ & 3,200 & \\
\hline \multirow{4}{*}{$3000 \mathrm{~m}$ obst } & 2017 & 632,033 & 16,562 & \multirow{4}{*}{0,600} & 709,040 & 21,173 & \multirow{4}{*}{0,632} & $526,393^{\mathrm{C}}$ & 17,750 & \multirow{4}{*}{0,991} & 547,350 & 6,028 & \multirow{4}{*}{0,006} \\
\hline & 2018 & 615,503 & 4,528 & & 703,600 & 38,717 & & $527,463^{\mathrm{C}}$ & 6,747 & & 550,790 & 8,747 & \\
\hline & 2019 & 632,420 & 19,815 & & 692,296 & 17,988 & & $529,97 \mathrm{AB}$ & 18,460 & & 568,386 & 6,566 & \\
\hline & 2020 & 622,320 & 23,058 & & 688,864 & 27,827 & & 528,723 & 12,505 & & 554,116 & 11,287 & \\
\hline \multirow{4}{*}{$5000 \mathrm{~m}$} & 2017 & 992,37 & 0,344 & \multirow{4}{*}{0,146} & 1015,17 & 14,767 & \multirow{4}{*}{0,135} & 850,340 & 20,455 & \multirow{4}{*}{0,520} & 891,745 & 25,688 & \multirow{4}{*}{0,208} \\
\hline & 2018 & 1009,59 & 1,585 & & 1047,95 & 23,562 & & 862,330 & 2,250 & & 878,510 & 6,052 & \\
\hline & 2019 & 995,40 & 14,149 & & 1033,91 & 17,333 & & 851,077 & 2,963 & & 881,362 & 8,202 & \\
\hline & 2020 & 991,05 & 12,825 & & 1032,72 & 19,052 & & 851,227 & 7,202 & & 872,554 & 4,310 & \\
\hline \multirow{4}{*}{$10000 \mathrm{~m}$} & 2017 & 2052,33 & 21,013 & \multirow{4}{*}{0,084} & $2108,19^{\mathrm{D}}$ & 30,889 & & 1759,63 & 8,950 & & 1810,90 & 8,140 & \\
\hline & 2018 & 2070,46 & 5,137 & & $2154,72^{\mathrm{D}}$ & 57,336 & & 1772,06 & 36,107 & & 1837,77 & 31,784 & \\
\hline & 2019 & 2078,28 & 2,930 & & $2140,17^{\mathrm{D}}$ & 46,975 & 0,001 & 1790,76 & 17,205 & 0,380 & 1830,11 & 10,408 & ,097 \\
\hline & 2020 & 2126,41 & 57,310 & & $2252,52 \mathrm{ABC}$ & 51,253 & & 1783,01 & 14,168 & & 1831,07 & 15,856 & \\
\hline
\end{tabular}

Leg.: ${ }^{\mathrm{A}}$ Diferença em relação a 2017; ${ }^{\mathrm{B}}$ Diferença em relação a 2018; ${ }^{\mathrm{C}}$ Diferença em relação a 2019; ${ }^{\mathrm{D}}$ Diferença em relação a 2020 
Tabela 8. Comparação entre os últimos medalhistas e não medalhistas do TB separado por sexo, prova e ano

\begin{tabular}{|c|c|c|c|c|c|c|c|c|c|c|c|c|c|}
\hline \multirow{3}{*}{ Provas } & \multirow{3}{*}{ Ano } & \multicolumn{5}{|c|}{ Feminino } & \multicolumn{7}{|c|}{ Masculino } \\
\hline & & \multicolumn{2}{|c|}{ Medalhistas } & \multicolumn{4}{|c|}{ Não Medalhistas } & \multicolumn{2}{|c|}{ Medalhistas } & \multicolumn{4}{|c|}{ Não Medalhistas } \\
\hline & & Média & DP & $\mathrm{P}$ & Média & DP & $\mathrm{P}$ & Média & DP & $\mathrm{P}$ & Média & DP & $\mathrm{P}$ \\
\hline \multirow{4}{*}{ Dist. } & 2017 & 6,50 & 0,18 & \multirow{4}{*}{0,564} & 6,05 & 0,15 & \multirow{4}{*}{0,709} & 7,75 & 0,04 & \multirow{4}{*}{0,012} & 7,55 & 0,06 & \multirow{4}{*}{0,523} \\
\hline & 2018 & 6,38 & 0,26 & & 6,04 & 0,10 & & $8,08^{C}$ & 0,10 & & 7,63 & 0,27 & \\
\hline & 2019 & 6,30 & 0,12 & & 5,98 & 0,04 & & $7,60^{\mathrm{B}}$ & 0,01 & & 7,48 & 0,10 & \\
\hline & 2020 & 6,40 & 0,02 & & 6,08 & 0,20 & & 7,92 & 0,25 & & 7,52 & 0,11 & \\
\hline \multirow{4}{*}{ Altur } & 2017 & $1,75^{c}$ & 0,04 & \multirow{4}{*}{0,041} & $1,65^{B}$ & 0,06 & \multirow{4}{*}{0,007} & 2,18 & 0,06 & \multirow{4}{*}{0,579} & 2,09 & 0,04 & \multirow{4}{*}{0,990} \\
\hline & 2018 & 1,81 & 0,01 & & $1,75^{A D}$ & 0,03 & & 2,21 & 0,02 & & 2,10 & 0,05 & \\
\hline & 2019 & $1,83^{A}$ & 0,03 & & 1,71 & 0,00 & & 2,19 & 0,02 & & 2,09 & 0,04 & \\
\hline & 2020 & 1,77 & 0,02 & & $1,66^{B}$ & 0,04 & & 2,22 & 0,05 & & 2,09 & 0,06 & \\
\hline \multirow{4}{*}{ Vara } & 2017 & 4,10 & 0,00 & \multirow{4}{*}{0,380} & 3,74 & 0,17 & \multirow{4}{*}{0,489} & $5,470^{D}$ & 0,87 & \multirow{4}{*}{0,038} & $5,07^{C D}$ & 0,20 & \multirow{4}{*}{0,002} \\
\hline & 2018 & 4,22 & 0,19 & & 3,78 & 0,16 & & $5,45^{D}$ & 0,09 & & 4,84 & 0,22 & \\
\hline & 2019 & 4,13 & 0,08 & & 3,64 & 0,25 & & 5,44 & 0,12 & & $4,55^{A}$ & 0,15 & \\
\hline & 2020 & 4,00 & 0,20 & & 3,64 & 0,05 & & $5,15^{A B C}$ & 0,18 & & $4,52^{A}$ & 0,21 & \\
\hline \multirow{4}{*}{ Tripl. } & 2017 & 14,09 & 0,49 & \multirow{4}{*}{0,342} & 12,98 & 0,16 & \multirow{4}{*}{0,164} & 16,30 & 0,10 & \multirow{4}{*}{0,701} & 15,60 & 0,31 & \multirow{4}{*}{0,588} \\
\hline & 2018 & 13,57 & 0,16 & & 13,07 & 0,17 & & 16,39 & 0,36 & & 15,32 & 0,44 & \\
\hline & 2019 & 13,44 & 0,54 & & 12,80 & 0,23 & & 16,64 & 0,61 & & 15,56 & 0,27 & \\
\hline & 2020 & 13,77 & 0,43 & & 12,79 & 0,32 & & 13,36 & 0,17 & & 15,43 & 0,33 & \\
\hline \multirow{4}{*}{ Disc. } & 2017 & 56,90 & 1,82 & \multirow{4}{*}{0,245} & 43,19 & 2,15 & \multirow{4}{*}{0,410} & 56,62 & 1,37 & & 52,18 & 2,39 & \\
\hline & 2018 & 62,22 & 4,30 & & 48,01 & 5,54 & & 55,79 & 0,34 & 088 & 51,89 & 2,71 & 299 \\
\hline & 2019 & 59,83 & 2,25 & & 45,32 & 2,97 & & 56,75 & 2,57 & 0,081 & 50,10 & 2,47 & 0,299 \\
\hline & 2020 & 58,67 & 2,90 & & 47,23 & 5,67 & & 55,60 & 3,28 & & 49,84 & 1,62 & \\
\hline
\end{tabular}

Leg.: ${ }^{\mathrm{A}}$ Diferença em relação a $2017 ;{ }^{\mathrm{B}}$ Diferença em relação a 2018; ${ }^{\mathrm{C}}$ Diferença em relação a 2019; ${ }^{\mathrm{D}}$ Diferença em relação a 2020 
Tabela 8. Comparação entre os últimos medalhistas e não medalhistas do TB separado por sexo, prova e ano.

\begin{tabular}{|c|c|c|c|c|c|c|c|c|c|c|c|c|c|}
\hline \multirow{3}{*}{ Provas } & \multirow{3}{*}{ Ano } & \multicolumn{6}{|c|}{ Feminino } & \multicolumn{6}{|c|}{ Masculino } \\
\hline & & \multicolumn{2}{|c|}{ Medalhistas } & \multicolumn{3}{|c|}{ Não Medalhistas } & \multicolumn{3}{|c|}{ Medalhistas } & \multicolumn{4}{|c|}{ Não Medalhistas } \\
\hline & & Média & DP & $\mathrm{P}$ & Média & DP & $\mathrm{P}$ & Média & DP & $\mathrm{P}$ & Média & DP & $\mathrm{P}$ \\
\hline \multirow{4}{*}{ Dard. } & 2017 & 59,04 & 3,03 & \multirow{4}{*}{0,466} & $52,79^{\mathrm{C}}$ & 2,87 & \multirow{4}{*}{0,052} & 74,31 & 0,48 & \multirow{4}{*}{0,208} & 68,61 & 3,37 & \multirow{4}{*}{0,075} \\
\hline & 2018 & 55,70 & 2,09 & & 47,41 & 3,55 & & 72,66 & 0,84 & & 66,41 & 2,02 & \\
\hline & 2019 & 56,43 & 2,24 & & $46,00^{\mathrm{A}}$ & 5,54 & & 70,55 & 2,47 & & 64,21 & 2,98 & \\
\hline & 2020 & 58,39 & 3,68 & & 47,76 & 1,94 & & 72,93 & 2,87 & & 59,38 & 9,37 & \\
\hline \multirow{4}{*}{ Mart. } & 2017 & 61,81 & 4,51 & \multirow{4}{*}{0,282} & $54,77^{\mathrm{C}}$ & 2,42 & \multirow{4}{*}{0,001} & 70,89 & 4,64 & \multirow{4}{*}{0,148} & 60,93 & 1,76 & \multirow{4}{*}{0,077} \\
\hline & 2018 & 61,49 & 3,58 & & $53,08^{\mathrm{C}}$ & 2,01 & & 70,43 & 3,55 & & 62,03 & 3,70 & \\
\hline & 2019 & 55,28 & 4,17 & & $48,84^{\mathrm{AB}}$ & 0,87 & & 68,81 & 2,27 & & 55,51 & 4,59 & \\
\hline & 2020 & 59,40 & 4,57 & & 51,80 & 1,88 & & 64,66 & 1,31 & & 56,71 & 5,95 & \\
\hline \multirow{4}{*}{ Peso } & 2017 & 17,14 & 0,88 & \multirow{4}{*}{0,970} & 14,49 & 1,17 & \multirow{4}{*}{0,361} & 19,77 & 0,72 & \multirow{4}{*}{0,935} & $17,398^{\mathrm{C}}$ & 0,85 & \multirow{4}{*}{0,041} \\
\hline & 2018 & 16,92 & 0,87 & & 14,12 & 0,75 & & 20,33 & 1,45 & & 17,33 & 1,42 & \\
\hline & 2019 & 16,90 & 0,72 & & 14,56 & 0,94 & & 20,03 & 1,07 & & $15,608^{\mathrm{A}}$ & 1,35 & \\
\hline & 2020 & 16,89 & 0,35 & & 13,32 & 1,62 & & 19,92 & 1,03 & & 15,90 & 0,72 & \\
\hline \multirow{4}{*}{ March. } & 2017 & $5971,66^{\mathrm{B}}$ & 101,913 & \multirow{4}{*}{0,013} & 6766,60 & 494,298 & \multirow{4}{*}{0,008} & 5105,33 & 201,420 & \multirow{4}{*}{0,641} & $5724,80^{\mathrm{D}}$ & 193,014 & \multirow{4}{*}{0,001} \\
\hline & 2018 & $6600,33^{\mathrm{AD}}$ & 260,430 & & $7351,2^{\mathrm{D}}$ & 70,878 & & 5343,33 & 18,185 & & $6163,60^{\mathrm{D}}$ & 321,812 & \\
\hline & 2019 & 6261,00 & 311,720 & & 6884,40 & 270,211 & & 5288,66 & 193,931 & & $5854,80^{\mathrm{D}}$ & 280,806 & \\
\hline & 2020 & $5872,49^{\text {в }}$ & 93,218 & & $6500,8^{\text {В }}$ & 348,101 & & 5202,32 & 331,572 & & 6791,49 АВC & 504,855 & \\
\hline \multirow{4}{*}{$\begin{array}{c}\text { Comb. } \\
\text { Hept/Dec }\end{array}$} & 2017 & 5867,66 & 152,329 & \multirow{4}{*}{0,051} & 5186,20 & 232,528 & \multirow{4}{*}{0,413} & 7516,00 & 262,022 & & 6716,00 & 469,083 & \\
\hline & 2018 & 5861,00 & 151,851 & & 4976,40 & 440,249 & & 7258,00 & 254,210 & 0100 & 6784,40 & 229,999 & 0420 \\
\hline & 2019 & 5549,00 & 133,090 & & 5131,40 & 254,301 & & 7795,66 & 185,990 & 0,109 & 6514,80 & 534,802 & 0,432 \\
\hline & 2020 & 5546,66 & 186,564 & & 4866,80 & 328,365 & & 7887,33 & 425,704 & & 6123,60 & 1022,746 & \\
\hline
\end{tabular}

Leg.: ${ }^{\mathrm{A}}$ Diferença em relação a 2017; ${ }^{\mathrm{B}}$ Diferença em relação a 2018; ${ }^{\mathrm{C}}$ Diferença em relação a 2019; ${ }^{\mathrm{D}}$ Diferença em relação a 2020 


\section{DISCUSSÃO}

É sugestivo que a pandemia da COVID no ano de 2020 tenha impactado os esportes de diversas formas, porém neste trabalho foi observado um número maior de atletas participantes no Troféu Brasil de Atletismo no ano de 2020, e o que poderia explicar isto seria a estratégia da CBAt para diminuir o impacto da pandemia, além de estender o prazo de obtenção de índices ao ano anterior, a decisão da CBAt em autorizar atletas sem índice, devido à falta de competições estaduais no ano, foi fundamental para que isso ocorresse.

Nesse contexto, fica evidente que apesar de interferir no calendário esportivo, a pandemia da covid 19 aparentemente não teve muito impacto no treinamento dos atletas em 2020, ou de fato, os treinadores encontraram soluções eficazes para diminuir os efeitos da pandemia. Tal fato pode ser corroborado por Oliveira Neto (2020) que em seu estudo constatou um aumento nas pesquisas por "treinamento online" e "treinamento em casa" durante o período pandêmico, e houve uma preocupação de treinadores e profissionais de educação física se reinventarem na sua prática profissional.

Também foi possível observar em nosso estudo, que houve um crescimento na participação de outros estados no TB, sobretudo no Nordeste. Com a criação do Troféu Manoel Trajano Dantas Neto, Norte-Nordeste de Adultos, com sua $1^{\text {a }}$ edição em 1977, atletas e clubes da região do norte vêm se destacando nos últimos anos com ranking e recorde regional próprios. Tanto, que o torneio regional foi um dos únicos a serem realizados pela CBAt no ano de 2020 após o início da pandemia no Brasil (CBAT, $2020 \mathrm{~g})$.

Apesar de termos encontrados diferenças significativas entre os anos de 2017-2020, tal fato não pode ser descrito como se os resultados do ano de 2020 fossem diferentes no Troféu Brasil. Das 40 (quarenta) provas analisadas (20 masculinas e 20 femininas), somente uma, os $10.000 \mathrm{~m}$ feminino, apresentou diferença significativa, e possivelmente, as mesmas atletas competiram na prova dos $5000 \mathrm{~m}$, a qual não foi encontrado diferenças no ano de 2020.

Ao analisar o desempenho os atletas separando-os por ordem de classificação na competição (medalhistas e não medalhistas), apresentou um aumento no número de diferenças significativas nas performances dos atletas não medalhistas, entretanto estas diferenças significativas existiram nas diferentes épocas esportivas, e não 
foi exclusividade do período pandêmico. Portanto, essas diferenças apesar de ser constante, não foi determinante no ano de 2020 .

Das analises realizadas, constatou-se que o atletismo brasileiro na competição Troféu Brasil de Atletismo não sofreu impactos no nível da performance de seus atletas, isto pode ser evidenciado de acordo com a CBAt (2021) que constatou que o Brasil mesmo em período pandêmico manteve atletas entre os melhores do ranking internacional.

\section{Limitações do estudo}

Não foram obtidas informações quanto ao treinamento dos atletas. Que adaptações foram feitas no planejamento da temporada de treinos ou nas adaptações na rotina diária de treino. Foram avaliados os resultados inferidos pelos resultados na competição.

\section{Aplicações Práticas}

Os resultados do estudo sugerem que é possível a obtenção de resultados no atletismo mesmo com grandes adaptações nos treinamentos, e mostram que os treinadores brasileiros são capazes de reorganizar o treinamento de seus atletas para superar dificuldades e imprevistos. 


\section{CONCLUSÃO}

É possível afirmar que os treinadores da elite do atletismo do brasileiro conseguiram passar pelo período pandêmico minimizando ao máximo a perda de desempenho dos atletas, sobretudo na competição Troféu Brasil de Atletismo.

As ações da CBAt de elevar o período de obtenção de índice e realizar a competição em dezembro parecem ter surtido efeito para abranger um maior número de participantes na competição.

Apesar de ser um ano atípico para treinamentos e competições, o ano de 2020 com a pandemia da Covid-19 não impactou a participação, nem os resultados dos atletas finalistas do Troféu Brasil de Atletismo 2020.

É recomendável que ocorra uma análise entre os participantes não finalistas, possivelmente, estes atletas juntamente com os atletas finalistas tenham sido mais impactados na sua rotina de treinamento e desempenho atlético. 


\section{REFERÊNCIAS}

BRASIL. Entra em vigor estado de calamidade pública no Brasil. Disponível em: $<$ https://www.gov.br/planalto/pt-br/acompanhe-o-planalto/noticias/2020/03/entra-em-vigorestado-de-calamidade-publica-no-brasil>. Acesso em: 10 dez. 2020.

CBAT. Em função da pandemia da COVID-19 e a prorrogação da quarentena, a entidade anunciou mais alterações em seu calendário. Disponível em:

$<\mathrm{http} / / /$ cbat.org.br/novo/noticias/noticia.aspx?id=16002>. Acesso em: 14 dez. 2020.

CBAT. CBAt divulga novo calendário de 2020. Disponível em:

$<$ http://www.cbat.org.br/novo/noticias/noticia.aspx?id=19079>. Acesso em: 11 dez. 2020.

CBAT. Érica Sena treina em esteira e sonha com o fim da quarentena. Disponível em: $<$ http://www.cbat.org.br/noticias/noticia.asp?news=18023>. Acesso em: 15 dez. 2020.

CBAT. Histórico - Uma Tradição de 75 anos, 2020d.

CBAT. CBAt confirma a realização do Troféu Brasil Caixa de Atletismo para São Paulo. Disponível em: $<$ http://www.cbat.org.br/novo/noticias/noticia.aspx?id=20300>. Acesso em: 8 jan. 2021.

CBAT. Troféu Manoel Trajano Norte-Nordeste Caixa promete fortes emoções. Disponível em: <http://www.cbat.org.br/novo/noticias/noticia.aspx?id=20276>. Acesso em: 12 jan. 2021.

CBAT. Brasil tem 17 atletas no TOP-20 da World Athletics de 2020. Disponível em: $<$ http://www.cbat.org.br/novo/noticias/noticia.aspx?id=25409>. Acesso em: 17 jan. 2021.

COI. Tokyo 2020, Here We Go: new dates, same commitment - Olympic News. Disponível em: <https://www.olympic.org/news/tokyo-2020-here-we-go-new-dates-same-commitment>. Acesso em: 10 dez. 2020.

DREWES, M.; DAUMANN, F.; FOLLERT, F. Exploring the sports economic impact of COVID-19 on professional soccer. Soccer \& Society, v. 0, n. 0, p. 1-13, 3 ago. 2020.

JÚNIOR, J. A. A.; MENDONÇA, G.; TOSCANO, J. J. O. Atuação das academias de ginástica durante a pandemia da Covid-19. Scientia Plena, v. 16, n. 10, 13 nov. 2020.

LEÔNIDAS DE OLIVEIRA NETO et al. Revista Brasileira de Fisiologia do Exercício. \#TreineEmCasa - Treinamento físico em casa durante a pandemia do COVID-19 (SARSCoV-2): abordagem fisiológica e comportamental, v. 19, p. 11, 2020.

LI, Q. et al. Early Transmission Dynamics in Wuhan, China, of Novel Coronavirus-Infected Pneumonia. New England Journal of Medicine, v. 382, n. 13, p. 1199-1207, 26 mar. 2020.

OMS. What is a pandemic? Disponível em:

$<\mathrm{http} / / / \mathrm{www}$.who.int/csr/disease/swineflu/frequently_asked_questions/pandemic/en/>. Acesso em: 15 dez. 2020.

OMS. Update 31 - Coronavirus never before seen in humans is the cause of SARS.

Disponível em: <https://www.who.int/news/item/16-04-2003-update-31---coronavirus-neverbefore-seen-in-humans-is-the-cause-of-sars $>$. Acesso em: 10 dez. 2020a. 
OMS. Advice for the public on COVID-19 - World Health Organization. Disponível em: $<$ https://www.who.int/emergencies/diseases/novel-coronavirus-2019/advice-for-public $>$. Acesso em: 10 dez. 2020 b.

SAMUEL RESENDE; DANIEL SILVEIRA. Em casa, atletas do CTE lutam para vencer o isolamentoUniversidade Federal de Minas Gerais, 20 jul. 2020. Disponível em: $<$ https://ufmg.br/comunicacao/noticias/em-casa-atletas-do-cte-lutam-para-vencer-oisolamento>. Acesso em: 9 dez. 2020

WONG, A. Y.-Y. et al. Impact of the COVID-19 pandemic on sports and exercise. Asia-Pacific Journal of Sports Medicine, Arthroscopy, Rehabilitation and Technology, v. 22, p. 39-44, 1 out. 2020.

WORLD ATHLETICS. Olympic qualification period suspended until 1 December 2020 | PRESS-RELEASES | World Athletics. Disponível em:

$<$ https://www.worldathletics.org/news/press-releases/olympic-qualification-suspended-2020>. Acesso em: 18 dez. 2021.

ZHENG, C. et al. COVID-19 Pandemic Brings a Sedentary Lifestyle in Young Adults: A CrossSectional and Longitudinal Study. International Journal of Environmental Research and Public Health, v. 17, n. 17, 192020. 


\section{ANEXOS}

\subsection{ANEXO 1 - Regulamento do Troféu Brasil}
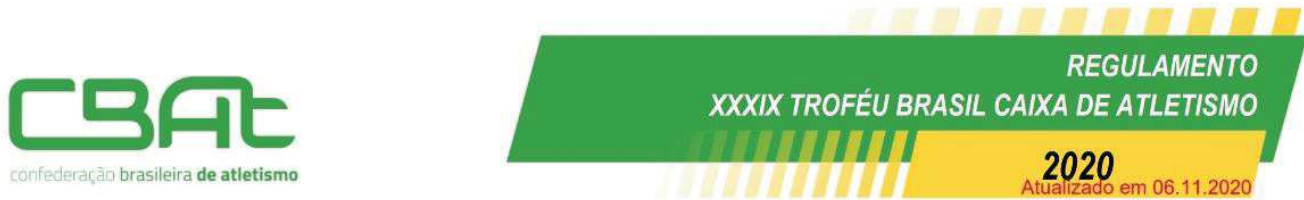

1. Geral

1.1. O "Troféu Brasil de Atletismo" é uma competição realizada anualmente que têm por propósito básico a difusão do Atletismo e a verificação do desenvolvimento de seu nível técnico no país, buscando com isto identificar a máxima performance dos atletas na modalidade e, quando for o caso, servir para a seleção de atletas visando participação em eventos internacionais.

1.2. O Troféu representativo da competição tem a denominação de "Troféu Brasil de Atletismo" e é entregue anualmente à entidade considerada vencedora da competição, que é aquela que conseguir somar o maior número de pontos nas provas masculinas e femininas.

1.3. Obrigatoriamente, o Troféu é realizado em pista oficial de Atletismo com certificação Classe 2 da WA, no mínimo.

\section{Direção e Arbitragem}

2.1. O Troféu é dirigido e organizado pela Confederação Brasileira de Atletismo (CBAt) e terá 4 (quatro) dias de duração, em data por ela estabelecida e com o apoio da federação sede do evento.

2.2. O Troféu é realizado segundo as regras da WA, as normas da CBAt, as contidas neste regulamento e as disposições emanadas das leis desportivas nacionais e internacionais.

2.3. A Direção da competição cabe a CBAt, que indica os Oficiais de Direção da mesma.

2.4. A arbitragem da competição é efetuada somente por Árbitros devidamente registrados na CBAt e em conformidade com o que dispõem as normas específicas da confederação.

2.5. Os atletas podem utilizar seus próprios implementos, com a condição dos mesmos serem aferidos pela equipe de arbitragem da competição.

2.6. Nas provas de saltos verticais, as alturas em que a barra será colocada para as provas são definidas pela Direção da competição e informadas no Congresso Técnico.

2.7. Cabe ainda à Direção da competição, a composição das séries e o sorteio de raias, a ordem de saída e a ordem de tentativas para as diversas provas, dentro do disposto nas regras da WA.

2.8. O programa-horário é elaborado pelo Departamento Técnico da CBAt, observando na distribuição de provas pelos dias de competição, o melhor horário para as provas, as instalações do estádio onde será realizada a competição e a transmissão ao vivo por televisão do evento.

\section{Participação}

3.1. Podem participar do Troféu somente as entidades de prática do Atletismo (Associações e Clubes) que estão plenamente regularizadas perante as federações a que estão filiadas e a CBAt, e que atendam às normas da legislação em vigor e a este Regulamento.

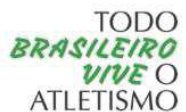




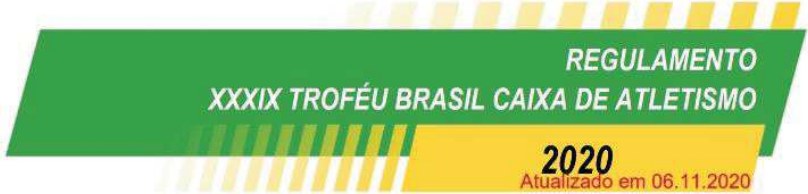

3.2. As despesas com transporte, hospedagem e alimentação das delegações são de responsabilidade das respectivas entidades participantes.

\section{Elegibilidade dos Atletas}

4.1. São condições para que o atleta participe do Troféu:

4.1.1. Ser brasileiro;

4.1.2. Estar devidamente registrado e inscrito na CBAt pela entidade que está representando na competição;

4.1.3. Não estar cumprindo penalidade imposta pela CBAt ou por suas filiadas;

4.1.4. Apresentar a carteira de atleta expedida pela CBAt;

4.1.5. Ter obtido os índices abaixo em cada prova, em competições oficiais, no período de $1^{\circ}$ janeiro de 2019 a 22 de novembro de 2020 :

\begin{tabular}{|c|c|c|}
\hline Masculino & Prova & Feminino \\
\hline $10.65 / 10.4$ & $100 \mathrm{~m}$ & $12.10 / 11.9$ \\
\hline $21.57 / 21.4$ & $200 \mathrm{~m}$ & $24.64 / 24.4$ \\
\hline $48.00 / 47.7$ & $400 \mathrm{~m}$ & $56.81 / 56.7$ \\
\hline 1.54 .58 & $800 \mathrm{~m}$ & 2.19 .20 \\
\hline 4.01 .22 & $1.500 \mathrm{~m}$ & 4.57 .44 \\
\hline 14.55 .90 & $5.000 \mathrm{~m}$ & 18.27 .89 \\
\hline 31.27 .51 & $10.000 \mathrm{~m}$ & 39.06 .00 \\
\hline 9.55 .20 & 3.000m com obstáculos & 12.43 .97 \\
\hline $14.88 / 14.6$ & $110 \mathrm{~m} / 100 \mathrm{~m}$ com barreiras & $14.81 / 14.6$ \\
\hline $55.39 / 55.1$ & $400 \mathrm{~m}$ com barreiras & $1.07 .47 / 1.07 .4$ \\
\hline 2.00 & Salto em Altura & 1.70 \\
\hline 4.50 & Salto com Vara & 3.30 \\
\hline 7.50 & Salto em Distância & 5.98 \\
\hline 15.06 & Salto Triplo & 12.35 \\
\hline 14.81 & Arremesso do Peso & 12.97 \\
\hline 47.73 & Lançamento do Disco & 42.68 \\
\hline 52.32 & Lançamento do Martelo & 46.08 \\
\hline 60.54 & Lançamento do Dardo & 42.67 \\
\hline 6.054 & Decatlo/Heptatlo & 4.327 \\
\hline 2.14 .21 & 20km Marcha Atlética & 2.24 .40 \\
\hline Sem índice & 50km Marcha Atlética & Sem índice \\
\hline Sem índice & Revezamento $4 \times 100 \mathrm{~m}$ & Sem índice \\
\hline Sem índice & Revezamento $4 \times 400 \mathrm{~m}$ & Sem índice \\
\hline
\end{tabular}

4.2. Somente são válidos índices obtidos em competições oficiais das federações filiadas à CBAt que constem dos calendários oficiais enviados para a Confederação e cujos resultados sejam homologados por esta; em competições oficiais da CBAt e em competições internacionais reconhecidas pelas federações nacionais de Atletismo dos países onde são realizadas.

4.2.1. Para efeito deste artigo, somente são considerados os resultados de competições que derem entrada no protocolo da CBAt até às 15.00 horas do dia 23 de novembro de 2020. Caso o resultado enviado seja de uma competição realizada 
a mais de 30 dias, o mesmo não será aceito a título de índices obtidos, sendo 5. Inscrições homologados pela CBAt.

5.1. As entidades participantes deverão realizar as suas inscrições on-line através do Sistema de Extranet da CBAt, de 27 a 30 de novembro de 2020.

5.2. Cada entidade participante pode inscrever quantos atletas desejar por prova e uma equipe nos revezamentos, com a condição de que para as provas individuais, os mesmos tenham obtido os índices mínimos estabelecidos nas condições do artigo 4.1.5 deste regulamento.

5.3. Para inscrição das equipes de revezamentos, os atletas que irão compor as mesmas não necessitam possuir índices mínimos em provas individuais, podendo ser inscritos somente nos revezamentos.

5.4. Cada atleta pode participar de, no máximo, três (3) provas individuais e dos revezamentos.

5.5. Os atletas com 16 e 17 anos (categoria menores) não podem participar das seguintes provas:

5.5.1. Masculino: Arremesso, Lançamentos e Decatlo.

5.5.2. Masculino e Feminino: $10.000 \mathrm{~m}$ rasos e Marcha Atlética.

5.6. Nenhuma entidade participante poderá inscrever atletas estrangeiros na competição.

5.7. Não é permitida a participação de atletas estrangeiros no Troféu.

5.8. Não é permitida a participação de qualquer atleta brasileiro em qualquer condição de "extra" ou similar na competição.

5.8.1. A CBAt pode, a seu exclusivo critério, autorizar a participação de atleta brasileiro como convidado na competição.

5.8.2. Na hipótese da participação de atletas autorizados pela CBAt conforme o parágrafo 5.8.1, os atletas nessa condição não têm acesso as finais das provas.

5.9. Excepcionalmente, para a edição de 2020 , no qual as medidas tomadas pelas autoridades de saúde em atenção a pandemia do COVID-19 impactaram no calendário nacional de competições, fica determinado que as 27 (vinte e sete) federações filiadas terão o direito de indicar até 5 (cinco) atletas para participação, sem índice mínimo, limitado ao máximo de 2 (duas) provas por atleta.

\section{Uniformes}

6.1. Os atletas devem utilizar, obrigatoriamente, o uniforme oficial de suas respectivas entidades.

6.1.1. Em nenhuma hipótese os uniformes poderão ter cores de patrocinadores das entidades;

6.1.2. As logomarcas de patrocinadores de clubes devem ser colocadas sobre o uniforme oficial da entidade inscrita.

6.1.3. Para efeito do constante do presente artigo, as entidades participantes devem inserir, obrigatoriamente, no Sistema de Extranet da CBAt, os desenhos com os 
modelos e cores de seus uniformes oficiais, que são utilizados pelos seus atletas nas competições, devendo manter isto atualizado antes do Troféu.

6.1.4. O atleta que comparecer para uma prova sem o uniforme oficial apresentado em conformidade com este artigo, é impedido de participar.

\section{Pontuação}

7.1. Haverá contagem em separado para o masculino e para o feminino e uma contagem geral para definir a equipe (clube) vencedora.

7.1.1. No caso de empate na classificação geral da competição e em cada naipe, de duas ou mais entidades, será considerada vencedora a que tiver obtido o maior número de primeiros lugares nas diversas provas. Persistindo o empate, o maior número de segundos lugares e assim sucessivamente até se determinar a equipe melhor colocada.

7.2. A pontuação atribuída por prova, para efeito da classificação por equipes, aos atletas 8 (oito) primeiros colocados, somente da fase final, será a seguinte:

\begin{tabular}{|c|r|}
\hline Colocação & Pontuação \\
\hline $1^{\circ}$ & 13 pontos \\
\hline $2^{\circ}$ & 8 pontos \\
\hline $3^{\circ}$ & 6 pontos \\
\hline $4^{\circ}$ & 5 pontos \\
\hline $5^{\circ}$ & 4 pontos \\
\hline $6^{\circ}$ & 3 pontos \\
\hline $7^{\circ}$ & 2 pontos \\
\hline $8^{\circ}$ & 1 ponto \\
\hline
\end{tabular}

7.2.1. A pontuação será considerada somente para os três primeiros atletas de uma mesma equipe. Nestes casos, a pontuação que seria aplicada aos demais atletas da mesma equipe, será atribuída aos atletas subsequentes na ordem de classificação, somente na fase final.

7.2.3. Nas provas de revezamentos e combinadas a pontuação acima é feita em dobro.

7.3. São acrescidos, aos pontos obtidos na prova, as bonificações abaixo:

7.3.1. Recorde do Troféu - 5 (cinco) pontos;

7.3.2. Recorde Brasileiro Adulto - 7 (sete) pontos;

7.3.3. Recorde Sul Americano Adulto - $10(\mathrm{dez})$ pontos:

7.4. Todo atleta que conseguir igualar ou superar o recorde, durante o transcorrer da competição, faz jus à bonificação na mesma prova.

7.5. A nenhum atleta é concedida mais que uma bonificação na mesma prova.

7.6. As bonificações são concedidas desde que as marcas melhoradas estejam em condições de serem homologadas. 

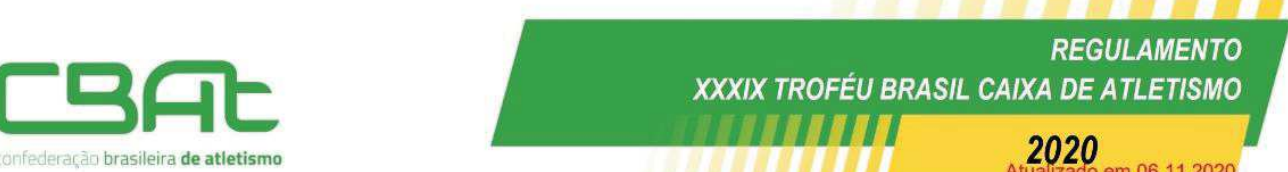

\section{Premiação de Equipes}

8.1. Serão agraciadas com troféus as equipes classificadas de $1^{\circ}$ ao $3^{\circ}$ lugar no masculino, no feminino e na classificação geral.

8.1.1. Haverá contagem em separado para o masculino e para o feminino e uma contagem geral para definir a equipe (clube) vencedora do Troféu.

8.1.2. Em caso de empate é considerada melhor classificada a equipe (clube) que tenha obtido o maior número de pontos em primeiros lugares; persistindo o empate, o maior número de pontos em segundos lugares e assim sucessivamente

\section{Premiação de Atletas}

9.1. Os atletas classificados em $1^{\circ}, 2^{\circ}$ e $3^{\circ}$ lugares de cada prova, recebem, como premiação, medalhas de vermeil, prata e bronze, respectivamente.

9.2. São agraciados com premiação especial os atletas (masculino e feminino) que forem considerados os melhores de cada Campeonato, por uma Comissão constituída por cinco treinadores indicados pelos participantes durante o Congresso Técnico.

\section{Provas}

10.1. São disputadas no Troféu as seguintes provas:

\begin{tabular}{|c|c|c|}
\hline Provas & Masculino & Feminino \\
\hline Corridas rasas & $\begin{array}{c}100 \mathrm{~m} \\
200 \mathrm{~m} \\
400 \mathrm{~m} \\
800 \mathrm{~m} \\
1.500 \mathrm{~m} \\
5.000 \mathrm{~m} \\
10.000 \mathrm{~m}\end{array}$ & $\begin{array}{c}100 \mathrm{~m} \\
200 \mathrm{~m} \\
400 \mathrm{~m} \\
800 \mathrm{~m} \\
1.500 \mathrm{~m} \\
5.000 \mathrm{~m} \\
10.000 \mathrm{~m}\end{array}$ \\
\hline Corridas com Barreiras & $\begin{array}{l}110 m \\
400 m\end{array}$ & $\begin{array}{l}100 m \\
400 m\end{array}$ \\
\hline Corrida com Obstáculos & $3.000 \mathrm{~m}$ & $3.000 \mathrm{~m}$ \\
\hline Marcha Atlética & $\begin{array}{l}20 \mathrm{~km} \\
50 \mathrm{~km}\end{array}$ & $\begin{array}{l}20 \mathrm{~km} \\
50 \mathrm{~km}\end{array}$ \\
\hline Revezamentos & $\begin{array}{l}4 \times 100 \mathrm{~m} \\
4 \times 400 \mathrm{~m}\end{array}$ & $\begin{array}{l}4 \times 100 m \\
4 \times 400 m\end{array}$ \\
\hline Saltos & $\begin{array}{l}\text { Distância } \\
\text { Altura } \\
\text { Triplo } \\
\text { Vara }\end{array}$ & $\begin{array}{l}\text { Distância } \\
\text { Altura } \\
\text { Triplo } \\
\text { Vara }\end{array}$ \\
\hline Arremesso e Lançamentos & $\begin{array}{c}\text { Peso }(7,26 \mathrm{~kg}) \\
\text { Disco }(2 \mathrm{~kg}) \\
\text { Dardo }(800 \mathrm{~g}) \\
\text { Martelo }(7,26 \mathrm{~kg})\end{array}$ & $\begin{array}{c}\text { Peso }(4 \mathrm{~kg}) \\
\text { Disco }(1 \mathrm{~kg}) \\
\text { Dardo }(600 \mathrm{~g}) \\
\text { Martelo }(4 \mathrm{~kg})\end{array}$ \\
\hline Provas Combinadas & Decatlo & Heptatlo \\
\hline
\end{tabular}


10.1.1. Nas provas de corrida em que não houver confirmação de inscrições suficientes para se compor séries eliminatórias, as mesmas são realizadas como semifinais no horário das eliminatórias e a final no horário previsto para a final.

10.1.2. Nas provas de pista em que não houver confirmação de inscrições para se compor séries semifinais, as mesmas são realizadas como final no horário previsto para a final.

10.1.3. Nas provas de campo quando houver treze (13) atletas confirmados ou mais, as mesmas serão realizadas como qualificação.

10.1.4. Nas provas de campo quando houver até doze (12) atletas confirmados, as mesmas serão realizadas como final no horário da final.

10.1.5. A seriação do revezamento será baseada pelo ranking brasileiro, compreendido o mesmo prazo indicado no Artigo $9^{\circ}$ item e) que é de $1^{\circ}$ agosto de 2019 a 22 de novembro de 2020.

\section{Congresso}

11.1. O Congresso do Troféu é instalado em sessão realizada em data definida pela CBAt.

11.2. O Congresso é dirigido pelo Diretor da Competição terá a auxiliá-lo um Secretário, por ele designado, e que, juntamente com o presidente da federação sede compõem a mesa diretiva.

11.3. O Congresso é realizado para discutir exclusivamente assuntos de ordem técnica, compreendendo resultados, normas de competição, confirmação, etc.

11.3.1. Podem participar do Congresso até dois (2) representantes de cada equipe inscrita, porém somente tem direito a voto um representante de cada entidade participante, devidamente credenciado.

11.3.2. As sessões do Congresso do Troféu não têm poderes para modificar o presente regulamento, podendo, entretanto, apresentar proposições a serem encaminhadas à CBAt para estudo quanto à viabilidade de sua inserção no ano seguinte.

\section{Protestos}

12.1. Todos os protestos a serem apresentados na competição devem ser feitos dentro do previsto na Regra 8 das Regras Técnicas da WA, incluindo o pagamento da taxa equivalente a U\$ 100.00 (cem dólares americanos).

12.2. Cabe a CBAt a indicação de um Júri de Apelação composto por 5 (cinco) membros, com a função de apreciar todo e qualquer recurso encaminhado por intermédio da Direção da Competição, ressalvada a competência da Justiça Desportiva.

12.3. Ressalvadas as hipóteses de competência do Superior Tribunal de Justiça Desportiva da CBAt, os protestos relativos à condição de um atleta para participar da competição devem ser apresentados, antes de seu início, ao Diretor da Competição.

12.3.1. Se o caso não puder ser resolvido antes da competição, o atleta deve participar 
"sob protesto", devendo o assunto ser oportunamente submetido ao Júri de Apelação.

\section{Divulgação e Promoção}

13.1. A CBAt detém todos os direitos de merchandising para quaisquer formas de propaganda e divulgação referentes à realização do Troféu.

13.2. A filmagem, transmissão pela televisão, gravação em vídeo, transmissão pela Internet, gravação ou transmissão por quaisquer meios eletrônicos disponíveis da competição, dependem de autorização da CBAt.

13.3. Anualmente, conforme a conveniência de merchandising da CBAt, à denominação Troféu Brasil de Atletismo podem ser acrescidos os nomes de eventuais patrocinadores.

\section{Disposições Finais}

14.1. Cabe a CBAt o direcionamento da montagem de todo o sistema de atendimento médico de emergência aos participantes da competição, durante a mesma.

14.2. Os casos omissos são resolvidos pelo Diretor da Competição dentro de suas atribuições ou pelo Departamento Técnico da CBAt. 
7.2. ANEXO 2 - Recordes do Troféu Brasil

\section{Recordes do Troféu Brasil}

Atualizado em 31/07/2020

\begin{tabular}{|l|l|l|l|l|l|}
\hline \multicolumn{5}{|c|}{ Masculino } \\
\hline \multicolumn{1}{|c|}{ Prova } & \multicolumn{1}{|c|}{ Marca } & \multicolumn{1}{c|}{ Atleta } & \multicolumn{1}{c|}{ Clube } & \multicolumn{1}{c|}{ Local } & Data \\
\hline 100 metros & $\begin{array}{l}10.02(- \\
0.6)\end{array}$ & $\begin{array}{l}\text { Paulo Andre Camilo } \\
\text { de Oliveira }\end{array}$ & E.C. Pinheiros & Bragança Paulista, SP & $14 / 09 / 2018$ \\
\hline 200 metros & $\begin{array}{l}20.15 \\
(1.3)\end{array}$ & $\begin{array}{l}\text { Aldemir Gomes da } \\
\text { Silva Junior }\end{array}$ & CRVG & $\begin{array}{l}\text { São Bernardo do } \\
\text { Campo, SP }\end{array}$ & $11 / 06 / 2017$ \\
\hline 400 metros & 44.82 & $\begin{array}{l}\text { Sanderlei Claro } \\
\text { Parrela }\end{array}$ & Flamengo & Rio de Janeiro, RJ & $04 / 06 / 1999$ \\
\hline 800 metros & $1: 44.21$ & Kleberson Davide & $\begin{array}{l}\text { EC Pinheiros } \\
\text { Asics }\end{array}$ & São Paulo, SP & $07 / 08 / 2011$ \\
\hline 1500 metros & $3: 37.53$ & $\begin{array}{l}\text { Joaquim Carvalho } \\
\text { Cruz }\end{array}$ & UE Funilense & Rio de Janeiro, RJ & 21/05/1995 \\
\hline 5000 metros & $13: 34.79$ & $\begin{array}{l}\text { Marilson Gomes dos } \\
\text { Santos }\end{array}$ & BM\&F Bovespa & Rio de Janeiro, RJ & $07 / 06 / 2009$ \\
\hline 10000 metros & $27: 58.83$ & $\begin{array}{l}\text { Marilson Gomes dos } \\
\text { Santos }\end{array}$ & BM\&F Bovespa & Rio de Janeiro, RJ & 04/06/2009 \\
\hline
\end{tabular}




\begin{tabular}{|c|c|c|c|c|c|}
\hline $\begin{array}{l}110 \text { metros com } \\
\text { barreiras }\end{array}$ & $\begin{array}{l}13.34 \\
(0.7)\end{array}$ & $\begin{array}{l}\text { Matheus Facho } \\
\text { Inocêncio }\end{array}$ & $\begin{array}{l}\text { Assem FADENP } \\
\text { SJC }\end{array}$ & São Paulo, SP & $19 / 06 / 2005$ \\
\hline $\begin{array}{l}400 \text { metros com } \\
\text { barreiras }\end{array}$ & 48.60 & Marcio Soares Teles & Orcampi Unimed & Bragança Paulista, SP & $01 / 09 / 2019$ \\
\hline $\begin{array}{l}3000 \text { metros com } \\
\text { obstáculos }\end{array}$ & $8: 26.06$ & $\begin{array}{l}\text { Altobeli Santos da } \\
\text { Silva }\end{array}$ & E. C. Pinheiros & $\begin{array}{l}\text { São Bernardo do } \\
\text { Campo, SP }\end{array}$ & $10 / 06 / 2017$ \\
\hline \multirow[t]{2}{*}{$\begin{array}{l}\text { Revezamento } 4 \times 100 \\
\text { metros }\end{array}$} & 38.33 & E.C. Pinheiros & E.C. Pinheiros & Bragança Paulista, SP & $15 / 09 / 2018$ \\
\hline & & \multicolumn{4}{|c|}{$\begin{array}{l}\text { Gabriel Oliveira Constantino, Jorge Henrique da Costa Vides, Derick de Souza } \\
\text { Silva, Paulo Andre Camilo de Oliveira }\end{array}$} \\
\hline \multirow[t]{2}{*}{$\begin{array}{l}\text { Revezamento } 4 \times 400 \\
\text { metros }\end{array}$} & 3:02.91 & Clube Arpoador Rio & $\begin{array}{l}\text { Clube Arpoador } \\
\text { Rio }\end{array}$ & São Leopoldo, RS & $23 / 05 / 1998$ \\
\hline & & \multicolumn{4}{|c|}{ Sanderlei Parrela, Edielson Tenório, Geraldo Maranhão, Flávio Godoy } \\
\hline $\begin{array}{l}20000 \text { m Marcha } \\
\text { Atlética - CM }\end{array}$ & $1: 21: 02.5$ & Moacir Zimmermann & AABLU & São Paulo, SP & $05 / 08 / 2011$ \\
\hline $20 \mathrm{~km}$ Marcha Atlética & $01: 21: 25$ & $\begin{array}{l}\text { Caio Oliveira de Sena } \\
\text { Bonfim }\end{array}$ & CASO & $\begin{array}{l}\text { São Bernardo do } \\
\text { Campo, SP }\end{array}$ & $10 / 06 / 2017$ \\
\hline Salto em Altura & 2.28 & Jessé Farias de Lima & Rede Atletismo & São Paulo, SP & $28 / 06 / 2008$ \\
\hline Salto em Distância & $8.31(1.4)$ & $\begin{array}{l}\text { Mauro Vinicius Hilário } \\
\text { Lourenço da Silva }\end{array}$ & BM\&F Bovespa & São Paulo, SP & $07 / 06 / 2013$ \\
\hline Salto Triplo & $\begin{array}{l}17.73 \\
(1.0)\end{array}$ & Jadel Gregório & $\begin{array}{l}\text { Clube de } \\
\text { Atletismo BM\&F }\end{array}$ & São Paulo, SP & $19 / 06 / 2005$ \\
\hline Salto com Vara & 5.71 & Fabio Gomes da Silva & BM\&F Bovespa & São Paulo,SP & $11 / 10 / 2014$ \\
\hline Arremesso do Peso & 22.00 & Darlan Romani & E.C. Pinheiros & Bragança Paulista, SP & $15 / 09 / 2018$ \\
\hline Lançamento do Disco & 63.13 & \begin{tabular}{|l} 
Ronald Odair de \\
Oliveira Julião
\end{tabular} & BM\&F Bovespa & São Paulo, SP & $30 / 06 / 2012$ \\
\hline
\end{tabular}




\begin{tabular}{|l|l|l|l|l|l|}
\hline Lançamento do Dardo 80.05 & $\begin{array}{l}\text { Júlio Cesar Miranda } \\
\text { de Oliveira }\end{array}$ & BM\&F Bovespa & Rio de Janeiro, RJ & $07 / 06 / 2009$ \\
& 75.47 & $\begin{array}{l}\text { Wagner José Alberto } \\
\text { Carvalho Domingos }\end{array}$ & BM\&F Bovespa & São Paulo,SP & $09 / 10 / 2014$ \\
\hline $\begin{array}{l}\text { Lançamento do } \\
\text { Martelo }\end{array}$ & 8393 & $\begin{array}{l}\text { Carlos Eduardo } \\
\text { Bezerra Chinin }\end{array}$ & BM\&F Bovespa & São Paulo, SP & $\begin{array}{l}07- \\
08 / 06 / 2013\end{array}$ \\
\hline Decatlo & & & & \\
\hline
\end{tabular}

\begin{tabular}{|c|c|c|c|c|c|}
\hline \multicolumn{6}{|c|}{ Feminino } \\
\hline Prova & Marca & Atleta & Clube & Local & Data \\
\hline 100 metros & $\begin{array}{l}11.07 \\
(0.0)\end{array}$ & $\begin{array}{l}\text { Ana Claudia Lemos } \\
\text { Silva }\end{array}$ & $\begin{array}{l}\text { Clube de } \\
\text { Atletismo BM\&F }\end{array}$ & São Paulo, SP & $06 / 06 / 2013$ \\
\hline 200 metros & $\begin{array}{l}22.48 \\
(1.0)\end{array}$ & $\begin{array}{l}\text { Ana Claudia Lemos } \\
\text { Silva }\end{array}$ & BM\&F Bovespa & São Paulo, SP & $05 / 08 / 2011$ \\
\hline 400 metros & 51.08 & $\begin{array}{l}\text { Maria Magnolia S. } \\
\text { Figueiredo }\end{array}$ & UE Funilense & São José Rio Preto, SP & $22 / 06 / 1996$ \\
\hline 800 metros & 1:59.82 & $\begin{array}{l}\text { Luciana de Paula } \\
\text { Mendes }\end{array}$ & Arpoador & Rio de Janeiro, RJ & $19 / 05 / 1995$ \\
\hline 1500 metros & $4: 11.80$ & Soraya Vieira Telles & ADC Eletropaulo & Rio de Janeiro, RJ & $27 / 06 / 1993$ \\
\hline 5000 metros & $15: 36.57$ & Cruz Nonata da Silva & BM\&F Bovespa & São Paulo, SP & $29 / 06 / 2012$ \\
\hline 10000 metros & $32: 15.72$ & Cruz Nonata da Silva & BM\&F Bovespa & São Paulo, SP & $27 / 06 / 2012$ \\
\hline $\begin{array}{l}100 \text { metros com } \\
\text { barreiras }\end{array}$ & $\begin{array}{l}12.89(- \\
0.7)\end{array}$ & Maíla Paula Machado & $\begin{array}{l}\text { Clube de } \\
\text { Atletismo BM\&F }\end{array}$ & São Paulo, SP & $19 / 06 / 2005$ \\
\hline $\begin{array}{l}400 \text { metros com } \\
\text { barreiras }\end{array}$ & 55.90 & Luciana França & Rede Atletismo & Rio de Janeiro, RJ & $07 / 06 / 2009$ \\
\hline $\begin{array}{l}3000 \text { metros com } \\
\text { obstáculos }\end{array}$ & $9: 49.22$ & $\begin{array}{l}\text { Tatiane Raquel da } \\
\text { Silva }\end{array}$ & IPEC & $\begin{array}{l}\text { São Bernardo do } \\
\text { Campo, SP }\end{array}$ & $01 / 07 / 2016$ \\
\hline
\end{tabular}




\begin{tabular}{|c|c|c|c|c|c|}
\hline $\begin{array}{l}\text { Revezamento } 4 \times 100 \\
\text { metros }\end{array}$ & 43.35 & BM\&F Bovespa & BM\&F Bovespa & Rio de Janeiro, RJ & $06 / 06 / 2009$ \\
\hline & & \multicolumn{4}{|c|}{ Jailma de Lima - Lucimar Moura - Rosemar Neto - Thatiana Ignacio } \\
\hline \multirow{2}{*}{$\begin{array}{l}\text { Revezamento } 4 \times 400 \\
\text { metros }\end{array}$} & 3.26 .68 & BM\&F Bovespa & BM\&F Bovespa & São Paulo, SP & $07 / 08 / 2011$ \\
\hline & & \multicolumn{4}{|c|}{$\begin{array}{l}\text { Geisa Aparecida Muniz Coutinho, Barbara Farias de Oliveira - Joelma das } \\
\text { Neves Sousa, Jailma Sales de Lima }\end{array}$} \\
\hline $\begin{array}{l}20000 \mathrm{~m} \text { Marcha } \\
\text { Atlética - CM }\end{array}$ & $1: 35.29 .6$ & Erica Rocha de Sena & BM\&F Bovespa & São Paulo, SP & $05 / 08 / 2011$ \\
\hline 20km Marcha Atlética & $1: 33.37$ & Erica Rocha de Sena & $\begin{array}{l}\text { ORCAMPI } \\
\text { UNIMED }\end{array}$ & São Paulo, SP & $07 / 06 / 2013$ \\
\hline Salto em Altura & 1.91 & $\begin{array}{l}\text { Orlane Maria Lima } \\
\text { dos Santos }\end{array}$ & $\begin{array}{l}\text { GE Sesi Santo } \\
\text { André }\end{array}$ & São Paulo, SP & $20 / 07 / 1989$ \\
\hline Salto em Distância & $6.99(-0.5)$ & Maurren Higa Maggi & BM\&F-CAIXA & São Paulo, SP & $29 / 06 / 2008$ \\
\hline Salto Triplo & $\begin{array}{l}14.58 \\
(2.0)\end{array}$ & Keila da Silva Costa & BM\&F Bovespa & São Paulo, SP & $07 / 06 / 2013$ \\
\hline Salto com Vara & 4.87 & $\begin{array}{l}\text { Fabiana de Almeida } \\
\text { Murer }\end{array}$ & BM\&F Bovespa & $\begin{array}{l}\text { São Bernardo do } \\
\text { Campo, SP }\end{array}$ & $03 / 07 / 2016$ \\
\hline Arremesso do Peso & 18.63 & $\begin{array}{l}\text { Elisangela Maria } \\
\text { Adriano }\end{array}$ & UE Funilense & Rio de Janeiro, RJ & $07 / 06 / 1999$ \\
\hline Lançamento do Disco & 64.75 & $\begin{array}{l}\text { Andressa Oliveira de } \\
\text { Morais }\end{array}$ & E.C. Pinheiros & Bragança Paulista, SP & $15 / 09 / 2018$ \\
\hline Lançamento do Dardo & 62.89 & $\begin{array}{l}\text { Jucilene Sales de } \\
\text { Lima }\end{array}$ & BM\&F Bovespa & São Paulo,SP & $11 / 10 / 2014$ \\
\hline \begin{tabular}{|l} 
Lançamento do \\
Martelo
\end{tabular} & 67.02 & $\begin{array}{l}\text { Mariana Grasielly } \\
\text { Marcelino }\end{array}$ & B3 Atletismo & $\begin{array}{l}\text { São Bernardo do } \\
\text { Campo, SP }\end{array}$ & $09 / 06 / 2017$ \\
\hline Heptatlo & 6188 & $\begin{array}{l}\text { Vanessa Chefer } \\
\text { Spinola }\end{array}$ & E.C. Pinheiros & $\begin{array}{l}\text { São Bernardo do } \\
\text { Campo, SP }\end{array}$ & $01 / 07 / 2016$ \\
\hline & & $\begin{array}{l}14.23(946)-1.81(991 \\
2.16 .01(879)\end{array}$ & $-13.07(732)$ & $16(965)-6.15(896)-4$ & $83(779)-$ \\
\hline
\end{tabular}

